\title{
Dynamic models of continental rifting with melt generation
}

\author{
Harro Schmeling \\ Goethe University, Institute of Earth Sciences, Frankfurt, Germany, Altenhöferallee 1, 60438 \\ Frankfurt, schmeling@geophysik.uni-frankfurt.de
}

Revised for Tectonophysics

Aug , 2009

Keywords: Rift zone, magmatism, continental break up, melting, lithospheric extension 


\section{Abstract}

Active or passive continental rifting is associated with thinning of the lithosphere, ascent of the asthenosphere, and decompressional melting. This melt may percolate within the partially molten source region, accumulate and be extracted. Two-dimensional numerical models of extension of the continental lithosphere-asthenosphere system are carried out using an Eulerian visco-plastic formulation. The equations of conservation of mass, momentum and energy are solved for a multi-component (crust - mantle) and two-phase (solid - melt) system. Temperature-, pressure-, and stress-dependent rheologies based on laboratory data for granite, pyroxenite and olivine are used for the upper and lower crust, and mantle, respectively. Rifting is modelled by externally prescribing a constant rate of widening with velocities between 2.5 and $40 \mathrm{~mm} / \mathrm{yr}$. A typical extension experiment is characterized by 3 phases: 1 ) distributed extension, with superimposed pinch and swell instability, 2) lithospheric necking, 3) continental break up, followed by oceanization. The timing of the transition from stage 1) to 2) depends on the presence and magnitude of a localized perturbation, and occurs typically after 100 - $150 \mathrm{~km}$ of total extension for the lithospheric system studied here. This necking phase is associated with a pronounced negative topography (“rift valley”) and a few $100 \mathrm{~m}$ of rift flanks. The dynamic part of this topography amounts to about $1 \mathrm{~km}$ positive topography. This means, if rifting stops (e.g. due to a drop of external forces), immediate additional subsidence by this amount is predicted. Solidification of ascended melt beneath rift flanks leads to basaltic enrichment and underplating beneath the flanks, often observed at volcanic margins. After continental break up, a second time-dependent upwelling event off the rift axis beneath the continental margins is found, producing further volcanics. Melting has almost no or only a small accelerating effect on the local extension value ( $\beta$-value) for a constant external extension rate. Melting has an extremely strong effect on the upwelling velocity within asthenospheric wedge beneath the new rift. This upwelling velocity is only weakly dependent on the rifting velocity. The melt induced sublithospheric convection cell is characterized by downwelling flow beneath rift flanks. Melting increases the topography of the flanks by $100-200 \mathrm{~m}$ due to depletion buoyancy. Another effect of melting is a significant amplification of the central subsidence due to an increase in localized extension/subsidence. Modelled magma amounts are smaller than observed for East African Rift System. Increasing the mantle temperature, as would be the case for a large scale plume head, better fits the observed magma volumes. If extension stops before a new 
ocean is formed, melt remains present, and convection remains active for $50-100 \mathrm{Myr}$, and further subsidence is significant.

\section{Introduction}

Continental rifts have attracted high attention for almost two centuries (see e.g. Rosendahl, 1987, for a historical perspective) because rift zones are closely related to magmatism which sometimes evolves into oceanic basins, and because of the occurrence of hydrocarbons associated with rift zones. A powerful tool to understand the mechanism of rifting and magmatism is physical modelling. As early as $1939 \mathrm{H}$. Cloos carried out his famous analogue model experiments on graben formation. Early models of rifting with magmatism have been carried out by Ramberg (1967, 1971), in which the mobility of low viscosity mobile magma bodies with respect to the rift faults has been studied. Since then, numerous model experiments, both analogue and numerical, have been carried out (see e.g. Corti et al., 2004, Huismans et al., 2005, and references therein for some more recent ones), however, the majority of which did not account for physical aspects of melt generation.

The importance of magmatism associated with rifting became clear after the concept of plate tectonics and plumes had been introduced. Rifting could be classified into active and passive (Sengör and Burke, 1978), which has been controversely discussed since then. As reviewed e.g. by Ruppel (1995), passive rifting begins with extensional thinning of the crust and mantle lithosphere due to farfield stresses generated by plate boundary forces or convective drag on the base of the lithosphere. Depending on the initial thickness of the lithosphere and the asthenospheric temperature, generation of melt and associated magmatism may begin either coevally with thinning or after some extension due to decompressional melting of the passively upwelling asthenosphere. These melts may either feed surface volcanism or may be intruded within the lower crust, compensating crustal thinning (Thybo and Nielsen, 2009; Sandrin and Thybo, 2008). Passive rifting is generally not associated with large scale topographic swells prior to rifting. In contrast, active rifting is traditionally associated with active mantle upwelling e.g. due to hot plumes or anomalously hot upper mantle. Consequently, large scale uplift, melt generation and magmatism predates rifting. A better understanding of the interaction between melt generation and rift dynamics may thus contribute to the above mentioned classification.

Upon extension and thinning of continental lithosphere asthenospheric material may exceed the solidus temperature and lead to melt generation (Foucher et al., 1982). Depending on the potential temperature, the original thickness of the lithosphere and the melting curve of peridotite the total amount of melt can be estimated under the assumptions of $1 \mathrm{D}$ kinematic 
mantle upwelling and no conductive cooling (McKenzie and Bickle, 1988). This approach has been applied successfully for the explanation of volcanic sequences at volcanic rich rifted continental margins (White et al., 1987; White and McKenzie, 1989). Given the extreme variability of abundance or absence of volcanic rocks at passive continental margins, and, at the same time the rather unique thickness of the oceanic crust, the $1 \mathrm{D}$ kinematic melt generation models appear too simplified. Bown and White (1995) showed that conductive cooling strongly reduces the total amount of melt if lithospheric extension is slow. Other parameters affecting the rift dynamics such as crustal rheology or the style of faulting have been suggested to explain magma-poor continental margin formation (Bowling and Harry, 2001; Lavier and Manatschal, 2006). Variations of magma production in rift zones and consequently at continental margins may also result from rift induced small scale convection (Buck, 1986; Mutter et al. 1988). While this mechanism has been proposed to be important for flank uplift of rifts, flexural isostatic rebound in response to rift related lithospheric unloading has been proposed to be more important (e.g. Weissel and Karner, 1989).

This effect of melting induced by dynamic rifting has been numerically modelled for the first time (to our knowledge) in a directly coupled way by van Wijk et al.(2001). They dynamically modelled passive rifting by extending a 3-layer continental lithosphere underlain by an asthenosphere. Decompressional melting was computed to calculate the timing of magmatism and total magma volumes. Interestingly, in the faster extension model (32 mm/a) melt was produced only after $10 \mathrm{Ma}$ of rifting. In their models migration of melt has not been accounted for, and no effect of melting on the dynamics of rifting has been considered. Using a compositionally uniform lithosphere-asthenosphere model with a kinematically prescribed half spreading velocity of $10 \mathrm{~mm} / \mathrm{a}$ Nielsen and Hopper (2002) modelled the melting evolution during the rifting and subsequent ocean opening phase. In contrast to the vanWijk et al. (2001) models they obtain high amounts of magma volumes already during the very first Ma after onset of rifting. This has also been found by similar corner-flow type models by Boutilier and Keen (1999) and by Ghods (2002). Although the effect of melting influenced rheology via dehydrational stiffening and density in the Nielsen and Hopper (2002) models, this did not have any effect on rifting dynamics as the extension has been kinematically prescribed at the surface in a corner-flow type of model.

While the majority of physical models and studies addressing melting and magmatism in rift zones use rifting dynamics or kinematics to predict melting parameters, only a few studies focussed on the effect of magmatism on rift dynamics. In a conceptual model Buck (2004) has proposed that lithospheric heating by mantle upwelling and related magma emplacement by 
dykes could significantly weaken the lithosphere and promote rifting. This mechanism has recently been corroborated by observed structures at the Ethiopian rift system Kendall et al. (2005). In another set of analogue models (e.g. Bonini et al., 2001; Corti et al., 2004) low viscosity bodies or layers of "magma" have been emplaced to study the mobilization of these magmas and their controlling effect on fault formation.

From the above review it appears that until now no fully coupled rift models including melting, melt migration and dynamic feed back on rifting have been carried out. As this coupled processes seems to be the key for understanding the interaction between rifting and magmatism, in the following sections such a model will be constructed (section 2.). Starting with a melt free rift model (section 3.1) melting behaviour and parameters such as the location of melting and solidification, melt extraction and the total melt volume will be studied in section 3.2. Different rifting velocities will be assumed in section 3.3. The effect of melting on rifting parameters such as the extension factor and flank topography will studied in section 3.4. In section 4 the results will be applied to the East African Rift System.

\section{Model approach}

Rifting within the continental lithosphere-asthenosphere system with melting can be described by the conservation equations of mass, momentum, energy, and composition for a two phase medium consisting of fluid (subscript $\mathrm{f}$, here basaltic melt) and highly viscous solid matrix (subscript s) (see McKenzie, 1984, Schmeling, 2000, 2006 for a discussion of these equations). While the two-phase description applies for partially molten regions within the lithosphere-asthenosphere system, it reduces to the one-phase solid flow formulation in regions below the solidus temperature. In this study elasticity is neglected, and the high Prandtl number approximation is used. The equations of mass for the melt and solid, respectively, are given by

$$
\begin{aligned}
& \rho_{f}\left(\frac{\partial \varphi}{\partial t}+\vec{\nabla} \cdot\left(\varphi \vec{v}_{f}\right)\right)=\Gamma \\
& \rho_{s}\left(\frac{\partial(1-\varphi)}{\partial t}+\vec{\nabla} \cdot\left((1-\varphi) \vec{v}_{s}\right)\right)=-\Gamma
\end{aligned}
$$

All variables and parameters and their meaning are defined in Table 1 and 2, together with the values assumed. The equation of momentum for the melt is given as a generalized Darcy law 
$\vec{v}_{f}-\vec{v}_{s}=-\frac{k_{\varphi}}{\eta_{f} \varphi}\left(\vec{\nabla} P+\rho_{f} g \delta_{i 3}\right)$

Neglecting surface tension the fluid pressure is equal to the pressure in the matrix phase.

Therefore the equation of momentum of the matrix contains the same pressure term:

$-\rho g \delta_{i 3}-\vec{\nabla} P+\frac{\partial \tau_{i j}}{\partial x_{j}}=0$

Equations (3) and (4) can be combined to eliminate $\nabla P$. For simplicity, equal heat capacity, heat conductivity and thermal expansivity for the melt and solid phases are assumed. Then the equation of energy can be written as

$\rho c_{p}\left(\frac{\partial T}{\partial t}+\vec{v} \cdot \vec{\nabla} T+\frac{\alpha g}{c_{p}} v_{z} T_{a b s}\right)=\vec{\nabla} \cdot(k \vec{\nabla} T)+\rho H+\psi-L \Gamma$

In (5) the velocity is the average velocity of the solid and melt, which can, at low melt percentage and not too high fluid velocity, be approximated by the solid velocity. Advection of composition (crust or mantle) can be written as

$\frac{\partial C_{k}}{\partial t}+\vec{v}_{s} \cdot \vec{\nabla} C_{k}=0$

These equations are complemented with the constitutive equations for rheology

$\tau_{i j}=\eta_{s}\left(\frac{\partial v_{s i}}{\partial x_{j}}+\frac{\partial v_{s j}}{\partial x_{i}}\right)+\delta_{i j}\left(\eta_{b}-\frac{2}{3} \eta_{s}\right) \vec{\nabla} \cdot \vec{v}$

permeability (which applies within the partially molten regions only)

$k_{\varphi}=k_{0} \varphi^{n}$

and density

$\rho=\sum_{k=1}^{3}\left[C_{k} \rho_{0 k}\left(1-\alpha T+\frac{\rho_{s}-\rho_{f}}{\rho_{s}} \varphi+c_{f} \cdot f+c_{e} \cdot e n r\right)\right]$ 
Compaction is neglected, i.e. the term $\eta_{b}-2 \eta_{s} / 3$ in equ (7) is set to 0 . Then equation (4) can be written as a biharmonic equation in terms of the stream function (see Schmeling, 2006). Depletion $f$ is advected with

$$
\frac{\partial f}{\partial t}+\vec{v} \cdot \vec{\nabla} f=\frac{\Gamma}{\rho_{f}}
$$

Melting and solidification are modelled using a simplified linear binary solid solution model (see Schmeling, 2006) with a solidus curve $\mathrm{T}_{\text {sol }}=1150^{\circ} \mathrm{C}+1.31 \cdot 10^{-3}{ }^{\circ} \mathrm{C} / \mathrm{m} * \tilde{z}$ and a solidus - liquidus difference of $400 \mathrm{~K}$. For simplicity, melting of crustal material is not accounted for.

Even though melt ascends by porous flow, melt may accumulate forming melt rich regions near the top of the partially molten zones (e.g. Schmeling, 2000). As discussed by Schmeling (2006) before reaching such high melt fractions, it is likely that melt collects in channels or dykes and leaves the melting zone on a time scale much shorter than the rifting time scale. This mechanism of melt ascent is approximated simply by extracting all melt exceeding a certain threshold value of $2 \%$ and emplacing it in a separate melt layer representing surface volcanics on top of the model (see e.g. Ruedas et al. 2003). While some mechanisms such as melt migration along the tilted solidification front at the top of the asthenosphere have been proposed to focus ascending melt near the rift axis at oceanic spreading ridges (Sparks and Parmentier, 1991 and others), it is not known whether these mechanisms also apply for early stages of continental rifting. For example analogue models of rifting with magma bodies near the Moho show that the magma moves towards the rift flanks (Bonini et al., 2001). Therefore, in this study the melt is simply emplaced using a bell shaped emplacement rate function $\varepsilon(\mathrm{x})$ with a half width of $50 \mathrm{~km}$. As in Ruedas et al. (2003) this melt layer is then advected with the moving surface of the rift zone by solving a $1 \mathrm{D}$ advection equation

$$
\frac{\partial h_{b}}{\partial t}+\frac{\partial\left(h_{b} v(\tilde{z}=0, x)\right.}{\partial x}=\varepsilon(x)
$$

A visco-plastic rheology is used defining an effective shear viscosity

$$
\frac{1}{\eta_{s}}=\frac{1}{\eta_{M C}}+\frac{1}{\eta_{d u c}}
$$

where $\eta_{M C}$ and $\eta_{d u c}$ are the "Mohr Coulomb" viscosity and ductile viscosity, respectively, given as

$$
\eta_{M C}=\frac{\tau_{\max }}{2 \dot{e}_{I I}}, \quad \eta_{d u c}=A_{k} \exp \left(\frac{E_{k}+V_{k} P_{L i t h}}{R T_{a b s}}\right) \exp (-a \phi) \tau_{I I}{ }^{1-n_{k}}
$$


where

$$
\tau_{\max }=A \tilde{z}+B
$$

is the Byerlee-type depth-dependent maximum deviatoric stress. Ductile rheologies for the upper crust, lower crust and mantle are assumed by taking parameters of Westerly granite, clinopyroxenite and dunite, respectively. These rheologies have been chosen as representatives of a relatively weak, quartz rich upper crust, a stronger, pyroxene rich lower crust and a strong olivine rich mantle, respectively. The laboratory parameters are taken from Kirby and Kronenberg (1987). The viscosity dependence on melt fraction, $a$, can be taken from laboratory data (Kohlstedt et al., 2000).

The equations are solved in 2D in a rectangular region of $400 \times 200 \mathrm{~km}$ representing the continental lithosphere with an underlying asthenosphere (Fig. 1).

Initial condititions. The system consists initially of a $35 \mathrm{~km}$ thick (= $20 \mathrm{~km}$ upper, $15 \mathrm{~km}$ lower) crust, about $45 \mathrm{~km}$ mantle lithosphere and an asthenosphere below. While the crustal units and the mantle are represented by the compositional fields $C_{1}, C_{2}$, and $C_{3}$, the mantle lithosphere - asthenosphere boundary is a thermal or rheological transition and depends on the initial temperature field. The initial temperature-depth profile is prepared by taking a timedependent $1 \mathrm{D}$ conductive solution at a specific time $t_{80}$ for the crust-mantle system (i.e. with depth-dependent heat conductivity and density as given in table 1). For this conductive solution an initially adiabatic layer with a potential temperature of $1400^{\circ} \mathrm{C}$ has been assumed, and the time $\mathrm{t}_{80}$ has been chosen as the time at which this $1 \mathrm{D}$ temperature field yields a surface heat flow of $80 \mathrm{~mW} / \mathrm{m}^{2}$ typical for active continental crust. This temperature field is associated with a depth of the $1200^{\circ} \mathrm{C}$ geotherm (depth of lithosphere asthenosphere transition) of $75.1 \mathrm{~km}$. To initiate rifting at $\mathrm{x}=0$, an elliptical thermal perturbation of $100 \mathrm{~K}$ has been added at a depth of $60 \mathrm{~km}$. Such lateral thermal variations may be typical within the lithosphere, and would correspond to lateral variations of surface heat flow of less than 5 $\mathrm{mW} / \mathrm{m}^{2}$.

Boundary conditions. As mechanical boundary conditions zero tangential stress is assumed at all four sides (free slip). Top and left sides have zero normal velocities, at the right side, a constant rifting velocity is prescribed down to a depth of $100 \mathrm{~km}$, which linearly decreases to 0 at $200 \mathrm{~km}$ depth. To balance this outflux, a vertical influx following a corner flow profile (Phipps Morgan, 1987) is assumed at the bottom. Temperature boundary conditions are $\mathrm{T}=0^{\circ}$ at the top and $1460{ }^{\circ} \mathrm{C}$ at the bottom (corresponding to a negligible heat flux at $\mathrm{t}=0$ ) are assumed. Zero conductive flux is assumed at both vertical boundaries. As these boundary 
conditions are symmetric with respect to $\mathrm{x}=0$, any rift process centred at $\mathrm{x}=0$ will be in pure shear rather than simple shear (Wernicke, 1985).

The above equations are solved with the code FDCON by Finite Differences combined with a marker approach (Schmeling, 2000; Weinberg and Schmeling, 1992; Schmeling et al., 2008). Resolution was 120 x 60 grid points for the Navier Stokes equation (4), 480 x 240 grid points for the equations 1,2,3,5,10, and $600 \times 300$ markers have been used for equation 6 .

\section{Results}

First, a reference model (model 1, see table 3) without melting will be shown, then the effect of melting will be discussed for model 2 and 3.

\subsection{Reference model without melting}

In a first model (model 1) a one-sided extension velocity of $2 \mathrm{~cm} / \mathrm{yr}$ is assumed. Fig. 2 shows the evolution of the compositional field. The marker field also gives an impression of the progressive deformation field. During the first Myr distributed extension takes place which starts to concentrate within a lithospheric region of about $100 \mathrm{~km}$ width, bounded by an almost undeformed lithosphere for $\mathrm{x}>100 \mathrm{~km}$. After about $1.5 \mathrm{Myr}$, crustal thinning becomes significant and the stretching factor $\beta$ at the rift axis reaches about $40 \%$. Stretching and thinning of the mantle lithopshere has a similar length scale. Upwelling of the asthenosphere is accompanied by a sublithopheric shear flow as can be verified be the inclined marker lines in the 2 Myr and later snapshots. After about 2 Myr a strong focussing of the deformation near the rift zone is visible $(\beta=100 \%)$, the upwelling velocity beneath the rift reaches a peak value of about $4.5 \mathrm{~cm} / \mathrm{yr}$ at 3.2 Myr, and at 3.4 Myr the crust is completely split into two parts $(\beta \approx 50)$ and an ocean opens. Subsequently the new (oceanic) lithospheric thickness approaches a typical square-root profile due to cooling by conduction, and the maximum upwelling velocity beneath the axis approaches $3.4 \mathrm{~cm} / \mathrm{yr}$.

It is interesting to look at the evolution of several relevant physical variables such as the temperature, viscosity and stress of model 1 (Fig. 3). At $t=0$ the initial thermal perturbation at $x=0$ is visible (c.f. section 2), but diffuses away at later stages. While the changes in the temperature field during the first Myr are moderate, the strong asthenospheric upwelling between 2 and 4 Myr rapidly brings up the hot asthenosphere. After 4 Myr temperatures above $1200^{\circ}$ occur at a depth as shallow as $3.3 \mathrm{~km}$.

The evolution of the viscosity field shows 3 different phases: At very early times $(\mathrm{t}=0-0.5$ Myr) the viscosity is laterally almost uniform. Vertically it shows three maxima within the 
upper crust, the lower crust and the mantle lithosphere, respectively. These viscosity maxima are related to three maxima of the deviatoric stresses (see the vertical profiles in Fig. 3, all taken at $x=0$ ). While in the upper crust, the Mohr-Coulomb strength (equ. 14) limits the maximum stress, the peaks in the lower crust and in the mantle lithosphere are controlled by the ductile strengths. During phase 1 there is still no clear strain localization near the future rift axis ( $\beta=6.5 \%$ at $x=0$ compared to an overall extension of $5 \%$ ). However, the high viscosity layer in the upper crust shows a weak, almost invisible long wavelength variation which may be associated with a pinch and swell instability (Ricard and Froidevaux, 1986). During phase $2(1-3 \mathrm{Myr})$ lithosphere necks at $\mathrm{x}=0$. The effective viscosity drops at the rift zone, as do the peak values of the deviatoric stress and the total lithospheric strength (area below stress profile). This stage corresponds to the maximum asthenospheric upwelling velocity. The local $\beta$-value rapidly increases. Finally, at phase 3 after $3 \mathrm{Myr}$, the lithosphere is completely split from its symmetric counter part, and the weak asthenosphere has merged with the low Mohr-Coulomb strength near the surface. Consequently the stress drops to a peak value of only $50 \mathrm{MPa}$ and below at the rift axis. The maximum deviatoric stress inside the freely drifting lithosphere has dropped to less than $15 \mathrm{MPa}$, which leads to a very high effective viscosity (which is truncated at a value of $10^{25} \mathrm{~Pa} s$ in the models). Phase 3 defines the opening of a new ocean.

Although the vertical velocity of the model is zero at the top, the surface topography $h_{\text {top }}$ can be determined from the vertical normal stress $\sigma_{\mathrm{zz}}=-\mathrm{P}+\tau_{\mathrm{zz}}$ at the surface by equating $\sigma_{\mathrm{zz}}$ with - $\rho_{01} \mathrm{~g} \mathrm{~h}_{\text {top }}$. It should be noted, that this topography includes dynamic and isostatic contributions, and assumes instantaneous adjustment to the vertical normal stress. However, no effects due to elasticity, erosion or sedimentation are included. As shown in Fig 4a, during phase 1 (distributed extension, weak long wavelength viscosity variations) the topography is small and characterized by a periodic pinch and swell like topography decaying with distance from the axis, with amplitudes between 50 and $100 \mathrm{~m}$. As necking at $\mathrm{x}=0$ progresses (phase 2, 1 - 3 Myr) the rift valley deepens significantly with flank uplift of about $200-250 \mathrm{~m}$. At early stages of phase 3 (3 Myr) the absence of continental crust in the central part leads to an ocean basin $1.5 \mathrm{~km}$ below the undisturbed continental surface, with a narrow and deep graben at the axis. The basin deepens as spreading continues and reaches $3.5-4 \mathrm{~km}$ depth at $6 \mathrm{Myr}$ which is still about $1.5-2 \mathrm{~km}$ less than the purely isothermal isostatic topography difference between an undisturbed continental block as assumed in this study (Table 1) floating in the mantle. The central graben after 3 Myrs is a consequence of the high tensile dynamic stresses 
associated with strain localization due the strong plastic weakening near the axis. The actual amplitude of this graben is beyond the resolution of the model.

This above difference between the modelled topography and a simple purely isostatic topography is due to dynamic forces associated with rifting induced flow and thermal buoyancy. This is demonstrated by model 1a, which is identical to model 1 , except that the kinematic rifting boundary conditions are set to zero after 3 Myr. Instantaneously, the shallow, strongly localized dynamic rifting and flow stresses at the axis change: the horizontal deviatoric stress at the rift axis switches from about +50 MPa (Fig 3) to about -50 MPa, thus becomes compressive. This is associated with a subsidence of the topography by more than 1 km (Fig. 4b). This dynamic contribution as given by the difference of topography before and after stopping rifting is shown as Fig 4c. While the exact value of the peak may be beyond the resolution of the model an order of $1 \mathrm{~km}$ is reliable. It is clearly seen that this dynamic topography effect has its maximum around $25 \mathrm{~km}$ from the rift axis, i.e. at the inner part of the rift flank. The magnitude of this change in stress and associated dynamic topography is quite large, given the relatively large one-sided rift velocity of $2 \mathrm{~cm} / \mathrm{yr}$ of this model. As the further evolution of this stopped model 1a shows, thermal subsidence leads to further subsidence, which already becomes visible after 20 Myr (last plot of Fig. 4b).

\subsection{Melt generation, continental break up and evolution of extracted volcanics}

As shown in model 1 in the previous section, asthenospheric upwelling accelerates in phase 3, and high temperatures are advected to shallow depth where they exceed the depth dependent solidus temperature. Model 2 has the same characteristics as model 1, except that melting is accounted for as described in section 2. The rheology of the mantle and of the depleted / enriched mantle are the same in that model, while partial melt reduces the viscosity according to equation (13). After $1 \mathrm{Myr}$ of extension (20 km of total widening) passive upwelling localizes near the axis and decompressional melting starts at a depth of $100 \mathrm{~km}$ (Fig. 5), well below the base of the lithosphere, defined by the $1200{ }^{\circ} \mathrm{C}$ geotherm at $75 \mathrm{~km}$ depth. During further extension and thinning, the melting region rapidly extends to shallow depth (2 - 3 Myr) and subsequently fills out the whole asthenospheric wedge, but with a maximum near the axis (6 Myr). This focussing near the central axis with a melt generation rate of more than $10 \% / \mathrm{Myr}$ is due to maximum upwelling velocities there. Melt ascends via porous flow (see equ. 3), however, as a maximum porosity threshold for retained melt of $2 \%$ is assumed above which all melt is extracted, percolation velocity is limited to about $0.9 \mathrm{~cm} / \mathrm{yr}$. As this 
percolating melt reaches the top of the partially molten zone, cooling from above leads to freezing and basaltic enrichment (blue regions). This freezing and enrichment zone coincides with the inclined base of the rifted lithosphere above about $50 \mathrm{~km}$ depth. This tilted zone of maximum enrichment is then advected passively sideways with the moving lithosphere (see inset in Fig. 5 for one snapshot), representing a remnant feature of magmatic enrichment or underplating originating during and after the most vigorous rifting phase. It is situated immediately beneath the tapered continental crust but dips sideways into the mantle lithosphere (upper enrichment zone in the inset of Fig 5). While during subsequent rifting the freezing zone near the top of the melt region remains essentially a steady state feature, it does not lead to further enrichment or a broadening of the enrichment zone, because at later stages freezing takes place within the depleted asthenosphere, only reducing the degree of depletion. A fraction of the enriched mantle circulates back to the rift axis (lower enrichment zone in the inset of Fig. 5). As this is also the case for cooled and depleted material (not shown), the net effect is a slight reduction of melt generation and an upward shift of its base (see the undulations of this base at 3 and 6 Myrs). While in the present model the enrichment zone only amounts up to about $1 \%$, melt extraction at the rift zone in nature may be incomplete, and some melt volumes may add to the enrichment zone modelled here.

While the melt generation rate strongly varies within the asthenospheric wedge (c.f. Fig. 5), the retained partial melt (not shown) almost evenly fills out the whole wedge region.

As only $2 \%$ melt is retained in the asthenosphere in model 2 , the extracted melt forms a basaltic layer which moves away from the rift axis with the velocity of the stretching plate. The growth and evolution of this layer is shown in Fig. 6. After onset of melting at about 2 Myr (c.f. Fig. 5), melt is first extracted at the rift axis and forms a volcanic layer with maximum thickness at the rift axis. As rifting proceeds, the maximum thickness of the basalt layer migrates to the sides. This might be surprising, as the maximum melt generation is centred at the rift axis (c.f. Fig. 5) and the extracted melt is emplaced directly above the place of origin. The reason for this central thinning (or thickening away from the axis) is the localized stretching of the rifting lithosphere near the axis. As has been shown by Ruedas and Schmeling (2008), the question of whether a rift valley or a swell forms at a spreading axis depends on the ratio of the width of magmatic emplacement $d_{m}$ to the width of the stretching zone $d_{s}$. For $d_{m}>d_{s}$ Ruedas and Schmeling predict a valley. After lithospheric necking has taken over (phase 2), the (half) stretching zone in model 2 is only $15-20 \mathrm{~km}$ wide, while the (half) melt generation and emplacement zone is about 50 - $100 \mathrm{~km}$ wide (Fig. 5). As rifting continues the initial peak reaches its maximum of about $8 \mathrm{~km}$ and moves sideways (the slight 
decrease in amplitude is due to numerical diffusion of the simple algorithm used to solve equ. 11). A new ocean forms and the model enters into the oceanic crust formation mode with an average crustal thickness of $5 \mathrm{~km}$ (Fig. 6b). The basaltic peak is situated above the upper edge of the tilted enrichment zones shown in Fig. 5. These peaks may explain the thick igneous crust along volcanic margins. They seem to be similar in nature as the peak extraction events after opening of an ocean modelled by Ghods (2002) and Boutilier and Keen (1999). However, in contrast to their models, here the full continental break-up is modelled, the spatial distribution of such magmatic peaks is predicted, and, as another difference to their models, $2 \%$ of melt is retained in the mantle.

In Fig. 6 also the total accumulated volume of extracted volcanics (in $\mathrm{km}^{3}$ per $\mathrm{km}$ rift axis) is given, which can be compared to observed volumes (see section 4).

It might be surprising that not only one peak forms during continental break up, but subsequently a second peak forms at about 10 Myr (Fig. 6). Inspection of the flow field (Fig. 7) reveals that this enhanced melt production is associated with a time dependent upwelling flow branch beneath the ocean side of the continental margin. This upwelling region migrates sideways following the moving continent, but decays as the oceanic lithosphere thickens with time (after 20 Myr or 400 km (half-) opening of the ocean the melt generation rate beneath the margin has dropped to less than $1 \% / \mathrm{Myr}$ in this model). This laterally migrating asthenospheric overturn instability is driven by thermal, melt and depletion buoyancy, similar to the migrating melt instability described by Schmeling (2000). However, in the present continental break up scenario it is assisted by the lateral movement of the continental lithospheric edge which additionally allows undepleted asthenospheric material to rise and melt (see also King and Anderson, 1995, for a thermally driven version of this process). As a consequence of the second melting event the oceanic lithosphere near the continental margin shows a characteristic stratification of depletion. Even though the melt produced beneath the moving continental edge is emplaced at the rift axis in this model (model assumption), it is to be expected that in nature it will directly add to the thick igneous crust at the magmatic margin during the first 100- $200 \mathrm{~km}$ of oceanic opening.

Before discussing the effect of melting on the rift process, a third end member model (model 3) is presented, in which no melt is extracted. Melt is only allowed to migrate by porous flow within the deforming matrix as formulated in section 2. In this case melt migrates upwards within the melting zone with a vertical percolation velocity peaking at approximately $23 \mathrm{~cm} / \mathrm{yr}$ at 3.6 Myr and a maximum melt fractions of about $7.5 \%$ are reached near the top of the melting zone (Fig. 8). It is interesting that the horizontal percolation velocities are at least 
one to two orders of magnitude smaller than vertical percolation velocities in most regions except near the solidification front. While only in the lower part of the partially molten wedge a very weak flow component is directed towards the axis, the horizontal percolation component points away from the axis in the upper part of the melting zone. Within the solidification front the horizontal component of the percolation flow reaches a narrow maximum, still only amounting up to only 10 to $60 \%$ of the maximum vertical percolation velocity. Because of the narrowness of this zone, the total distance of melt transport due to horizontal percolation is very minor. Interestingly, this horizontal flow component is also directed away from the rift axis. This flow may be interpreted as a consequence of a local under-pressure associated with a volume decrease of the partially molten composite during freezing (Schmeling, 2000; Šrámek et al., 2007). As visible in Fig. 8, at later stages (between 3 and $6 \mathrm{Myr}$ ) melting occurs within the entire asthenospheric wedge, however, highest melt fractions and particularly melt generation rates are confined within a rather narrow vertical channel at the rift axis. This narrowing effect is caused by a strong focussing of the asthenospheric upwelling flow pattern which evolves as a consequence of melt weakening and increased buoyancy. For mid-ocean ridges this effect has already been described by $\mathrm{Su}$ and Buck (1993). Between 2 and 4 Myr the asthenospheric upwelling velocity exceeds 20 $30 \mathrm{~cm} / \mathrm{yr}$ (with a peak value of $62 \mathrm{~cm} / \mathrm{a}$ ) within an upwelling zone of $20 \mathrm{~km}$ half width (see inset in Fig. 8). Together with the high melt percolation velocity, melt rises during this phase with more than half a meter per year at the rift axis. From this model it may be inferred that concentration of magmatism near the rift axis is mostly controlled by narrowing of the mantle flow within the asthenospheric wedge rather than by lateral melt flow due to percolation. It should, however, be noted that these velocities only give a rough estimate as they strongly depend on the rheological properties of the melt zone, the melt viscosity and permeability law, all quantities which are not well known. Interestingly, the strong asthenospheric rising flow is associated with an adjacent downwelling flow beneath the rift flank, in which melt is actually transported faster downward than it rises by porous flow. As a consequence, compressional freezing as opposed to decompressional melting occurs in the light blue region in Fig 8. At the top of the melting zone, percolating melt encounters solidification which is visible by the dark blue band (Fig. 8). This freezing front is very narrow and produces a narrow layer band of high basaltic enrichment ( $>15 \%)$ at the base of the newly formed lithospheric base (similar to but much stronger than the band shown in the snapshot for model 2, c.f. Fig. 5). 


\subsection{Effect of different rifting velocities}

As the one-sided rifting velocity of $2 \mathrm{~cm} / \mathrm{yr}$ may be too large for many rifts two models (model 5 and 6) have been run with $5 \mathrm{~mm} / \mathrm{yr}$ and $1.25 \mathrm{~mm} / \mathrm{yr}$, respectively (Fig. 9). Reducing the rift velocity by a factor of 4 or 16 with respect to the previous models allows more conductive cooling during the rifting phase. Lithospheric and crustal thinning becomes broader for the slower rifting rates, resulting in a reduced axial thinning compared to model 2 (c.f. Fig.9, panels in $2^{\text {nd }}$ row and Fig 2 at $3 \mathrm{Myr}$ ). Despite a reduction of rifting velocity by a factor 4 or 16 the, deviatoric stresses within the lithosphere have almost the same magnitude as in model 2. The effective viscosity structures are quite similar, however, the thicker mantle lithosphere takes up more stress than in the fast rifting case. As the stresses of model 2 (2 $\mathrm{cm} / \mathrm{yr}$ ) and 5 ( $5 \mathrm{~mm} / \mathrm{yr}$ ) are very similar during the whole rifting stage, the surface topography of model 5 is very similar to that of the fast model (c.f. Fig 4), the exception being the deep central valley of model 2 associated with the ocean opening. The broader deformation zone of the very slow rifting model (model 6) produces a couple of pinch-and-swell structures before rifting focuses at the axis (Fig. 9, upper left panel).

Comparing the melt generation rates (Fig. 9, lower right panel, Fig. 5 at 3 Myr) gives the surprising result that the slower model $5(5 \mathrm{~mm} / \mathrm{yr})$ has a significantly higher melt generation rate compared to model 2 during the early melting phase (if stages of similar total extension are compared). To reach the total extension amount of $120 \mathrm{~km}$, model 5 needs 4 times longer than model 2. During this time conductive cooling thickens the thermal boundary layer at the base of the lithosphere so that once asthenospheric upwelling starts within the evolving asthenospheric wedge, the convective instability is stronger compared to the earlier stage associated with model 2. Stronger convection leads to a higher melt generation rate. Even for the very slow model 6 (Fig. 9, lower left panel) the melting rate due to asthenospheric convection is comparable to the melting rate of the fast model 2. Both slow models show a significantly higher freezing rate within the upper part of the partially molten zone. .

\subsection{Effect of melt and melt generation on rifting dynamics and topography}

As the models 1, 2 and 3 are identical except for the occurrence of melting, they allow evaluation of the effect of melting on the dynamics of rifting. The occurrence of melting and the presence of melt may affect the rheology directly by (a) the presence as a weak phase which enhances diffusion, and (b) by dehydration and stiffening of the matrix if water is present (e.g. Kohlstedt and Hirth, 1996; Kohlstedt et al., 2000). While the first effect is accounted for in the present model, dry conditions are assumed in this study prohibiting 
dehydration stiffening (but see e.g. Boutilier and Keen (1999) and Ghods (2000) who studied this effect). Further effects of melting in models 2 and 3 are (c) to reduce the temperature due to the consumption of latent heat, and (d) to decrease density due to the presence of retained melt. Both effects (c and d) influence the non-Newtonian rheology and buoyancy. Let us first evaluate roughly effect (a): The presence of $2 \%$ (or $7.5 \%$ as in model 3) melt decreases the viscosity via the rheology equation 13 by a factor of about 0.5 (or one order of magnitude). Estimating effect (c) shows that melting up to a degree $12 \%$ (model 2 and 3 at $3 \mathrm{Myr}$ ) cools the upwelling asthenosphere by about $30 \mathrm{~K}$ (c.f. the latent heat, table 2), which can be verified by comparing the temperature fields of model 1 and 2 (not shown). Given the activation energy of the olivine creep law (Table 1) such a temperature decrease within the rising asthenosphere is able to increase the effective viscosity by a bit more than a factor 2 . On the other hand, $2 \%$ (or $7.5 \%$ ) retained melt decreases the mean density by about $0.2 \%$ (1\%) or 8 $\mathrm{kg} / \mathrm{m}^{3}\left(30 \mathrm{~kg} / \mathrm{m}^{3}\right)$ which is equivalent to an increase in temperature of about $80 \mathrm{~K}(300 \mathrm{~K})$. Thus the retained melt effect on buoyancy exceeds the thermal buoyancy effect due to cooling by consumption of latent heat. As the above density difference $\Delta \rho$ in the partially molten rising asthenosphere acts on a scale $h_{p m}$ of 50 - $100 \mathrm{~km}$ (c.f. its vertical extent, e.g. Fig. 5), it increases the deviatoric stress within the asthenosphere and particularly in the lithosphere near the rift axis by an amount of order of $\Delta \tau=\Delta \rho g h_{p m}$ or $3-6 \mathrm{MPa}$ for model 2. In our model this is roughly $3-6 \%$ of the stress level $\tau_{\text {II }}$ of the rifting lithosphere (c.f. Fig. 3). Given a layer with visco-plastic power law rheology with an exponent $\mathrm{n}$ and a stress delimiter $\tau_{\max }$ (equations 12 -14), the relative change of effective viscosity with relative change of stress, i.e. $d\left(\ln \eta_{s}\right) / d\left(\ln \tau_{I I}\right)$, varies between 1-n and $-\infty$ depending on how close the deviatoric stress has approached $\tau_{\max }$. Thus locally (preferently in the plastically yielding layer at the very rift axis) the effective viscosity decreases significantly, even for an increase of the deviatoric stress as small as $3-6 \%$. As a matter of fact, the three effects (a), (c) and (d) partly work in opposite directions, and for model 2 it is difficult to predict which of them dominates. Inspecting the effective viscosity fields at an arbitrary time 3 Myr (not shown) also does not give a clear answer: within the sub-rift asthenosphere the effective viscosity seems to be decreased by a factor between 1.5 and 5 in the presence of melt, within the plastic zone at the very rift axis it decreased locally even more, but within the adjacent continental lithosphere it increased.

If one compares the local extension factor $\beta$ of the two different models 1 and 2 at the rift axis, surprisingly the dependence of $\beta$ on the total extension does not differ at all (Fig. 10a). Indeed, the curves of model 1 and 2 (without and with melting + extraction) are almost the 
same, with the melt model even being marginally slower. Obviously the above mentioned effects partly cancel out, and the remaining weakening effect due to melting leads to a slightly broader distribution of extension than without melting, i.e. a slightly smaller $\beta$-value at the axis and a slightly larger $\beta$-value at greater distance. As the external extension rate has been kept constant, the rift evolution seems to be controlled by the early stage of the necking phase (where no melt is present). The onset of melting with just a few \% melt as in model 2 is too late and the melting effect is too weak to considerably alter the lithospheric extension evolution. It should, however, be noted that this finding applies only to the kinematic case of a constant external extension rate. If extension is driven by a constant force, the effect of melting might be stronger.

If melt is retained in the melting zone (model 3), higher melt fractions lead to a significantly stronger weakening effect (while the effect of latent heat is roughly the same), and to higher buoyancy. In this case, a visible, but not significant acceleration of necking is observed (Fig. 10a), lithospheric break up occurs about a total extension of $10 \mathrm{~km}$ earlier. Again, it might be surprising that strong weakening due to melting and additional buoyancy, which amounts up to one and two orders of magnitude within the asthenospheric wedge at $120 \mathrm{~km}$ extension, affects the extension factor only moderately. Again, this can be explained by the kinematic rather than dynamic control of the boundary condition.

Reducing the rifting velocity by a factor of 4 or 16 a higher total extension is needed for the onset of localized extension (dashed and dash-dotted curves in Fig 10a), however, the effect is rather small, at least for model 5.

While melting hardly affects the lithospheric extension or thinning (for kinematic boundary condition), a strong effect is observed for the flow velocities within the asthenosphere wedge beneath the rift zone (Fig. 10b). Without melting, the peak value of passive asthenospheric upwelling does not exceed $5 \mathrm{~cm} / \mathrm{yr}(=2.5$ times the (half-)extension velocity). Melt weakening and buoyancy of model 2 (2\% retained melt) allows asthenospheric upwelling of more than $15 \mathrm{~cm} / \mathrm{yr}$ (= 7.5 times the (half-) extension velocity). Literally this means that $1 \mathrm{~km}$ of horizontal widening may extract the melt from a vertical column of 7.5 km high. This effect is highly amplified for model 3, in which no melt is extracted but all generated melt percolates by porous flow and eventually solidifies when reaching the solidus temperature. Rheological weakening due to the presence of higher melt fractions and power law rheology in combination with an increased melt buoyancy lead to a strong upwelling velocity within the partially molten region, peaking at $62 \mathrm{~cm} / \mathrm{yr}$ at $2.2 \mathrm{Myr}(88 \mathrm{~km}$ total extension). A second peak of about $22 \mathrm{~cm} / \mathrm{yr}$ occurs at $3.5 \mathrm{Myr}(140 \mathrm{~km})$, which is the time 
the continental crust is completely split into two parts. At late stages at well developed oceanic spreading, the upwelling velocities at the spreading axis are similar for the three cases.

Reducing the rifting velocity by a factor 4 or 16 still produces episodes with strong upwelling velocities (dashed and dash-dotted curves in Fig. 10b). Peak velocities are 24 or 64 as large as the half rifting velocities, respectively. Interestingly, model 5 ( $5 \mathrm{~mm} / \mathrm{yr})$ has a maximum at about $75 \mathrm{~km}$ of extension, i.e. at an earlier rift stage than the faster model 2 . As discussed above, this can be explained by a more unstable thermal boundary layer which developed during the longer time associated with slow rifting.

It is interesting to study the effect of melting on the evolution of surface topography (Fig. 11). While one would expect that the additional melt and depletion buoyancy (see table 2) would increase the topography compared to the "no melting" case 1, this is only observed for the rift flanks. There, the topography of both models 2 and 3 is about 100 to $125 \mathrm{~m}$ higher than the rift flank without melt (model 1). The profiles of models 2 and 3 are almost identically at the rift flank, because they have almost the identical spatial distribution of depletion. The amount of enhanced flank uplift is in agreement with the $50 \mathrm{~km}$ thick mantle layer of less dense, depleted material. It might be surprising that near the rift axis melt buoyancy of models 2 and 3 does not increase topography. On the contrary, the central rift region strongly subsides due to the strong shallow sublithospheric diverging flow above the focussed upwelling flow limb (see e.g. the streamlines in the inset of Fig. 8). This flow configuration obviously leads to local extensional stresses and an under-pressure at the rift axis, which dynamically pulls the surface down. This deep rift graben is even more pronounced for the model with more buoyancy (model 3). The deep graben is bounded by narrow topographic highs at the positions ( $x=10 \mathrm{~km}$ for model 2 and $18 \mathrm{~km}$ for model 3), where the split continental crust tapers off. The amount of central subsidence of 7 to $7.5 \mathrm{~km}$ of models 2 and 3 seems to be unrealistically deep. However, it should be noted that in model 2 at that time already $8 \mathrm{~km}$ of basaltic crust has been extracted (see Fig. 6) which has isostatically to be added to the model, while in model 3 the melt has percolated sideways, and actually peridotitic mantle surfaces at the spreading axis without being covered with any crustal material. 


\section{Discussion}

\subsection{Application to the East African Rift System}

The volumes of extracted magma of the present model may be compared to volumes of erupted volcanics of natural rift zone. For the East African Rift System (EARS) erupted volumes have been estimated (see e.g. Kazmin, 1980 and references therein). If normalized to a unit rift length, these volumes are for the Western branch of the East African Rift System (EARS) $50 \mathrm{~km}^{3}$ per km rift length, for the Kenya rift $220 \mathrm{~km}^{3} / \mathrm{km}$, and for the Ethiopian rift branch $400 \mathrm{~km}^{3} / \mathrm{km}$. In model 2 such magma volumes can be extracted after $2.25 \mathrm{Myr}, 3 \mathrm{Myr}$ and $4.5 \mathrm{Myr}$ or $90 \mathrm{~km}, 120 \mathrm{~km}$ and $180 \mathrm{~km}$ of full extension, if a constant $4 \mathrm{~cm} / \mathrm{yr}$ full extension rate is assumed, respectively. However, these values cannot be compared directly to the evolution of the EARS because 1) the present extension velocities are significantly smaller than the full model extension rate of $4 \mathrm{~cm} / \mathrm{yr}: 1-4 \mathrm{~mm} / \mathrm{y}$ for the Western EARS and the Kenyan rift and $5 \mathrm{~mm} / \mathrm{yr}$ rift perpendicular for Ethiopian rift (Stamps et al., 2008), and 2) these extension velocities have probably varied with time, while they are kept constant in the model. The ages of the volcanics in East Africa are significantly older than the ages of model 2, but comparable to models 5 and 6: For the Western EARS and the Kenya rift the volcanic ages are between recent and $18 \mathrm{Ma}$, for the Ethiopian rift 35 - 45 My (Nyblade et al., 2002). Given the models with different rifting velocities the volcanic volumes of the EARS rifts of different widths can be compared with modelled magma extraction amounts of modelled rifts with comparable total extension. Fig. 12 shows the extracted magma volumes of model 2 as a function of total (double sided) extension. From tectonic maps (e.g. Chorowicz, 2005) widths of the rift systems can be roughly estimated by the distance of the major graben faults (horizontal bars in Fig. 12). It appears that these natural widths are roughly half the corresponding widths of the synthetic rift model. Thus, even though extension is significantly slower in the EARS than in model 2, the same amounts of magma are extracted at systematically smaller extension widths, or in other words, systematically more magma is extracted at same extensions widths. The slower model 5 (dashed curve) produces magma volumes already at somewhat smaller extensions, but still lies below the observed values. The slowest model 6 generates only minor melt volumes.

One possibility to obtain higher magmatic amounts is that the asthenosphere beneath the three rifts of the EARS are systematically hotter than in the models. As the mantle temperature of model 2 is capable to produce normal oceanic crust after continental break up, it represents normal mantle temperatures. A systematically higher mantle temperature is an 
indication for a laterally wide spread plume anomaly beneath the three evaluated rifts of the EARS. In another model (model 4) this possibility is tested by increasing the bottom temperature of the model by $100 \mathrm{~K}$ within a bell shaped region of half-width $100 \mathrm{~km}$, but dropping the initial elliptical thermal perturbation (c.f. Fig. 1). As a result, as the red curve in Fig. 12 indicates, melting and melt extraction occurs earlier (after $65 \mathrm{~km}$ total extension), but due to the absence of a local perturbation lithospheric necking (phase 2, see above) is delayed until $150 \mathrm{~km}$ of extension. Altogether, significantly more magma is extracted than for models 2, 5, and 6. If these models are associated with the "passive rifting" mode, this result indicates that the EARS is an "active rift" significantly affected by a plume.

One might argue that models 2, 5, and 6 produce smaller amounts of magma than observed because too much melt (2\%) is retained in the mantle. However, if this number would be smaller in nature, mantle temperature and/or the melting curve would have to be adjusted to calibrate the model to produce the correct thickness of normal oceanic crust after continental break up. Consequently, similar amounts of magma as shown in Fig. 12 (black curve) would be extracted as a function of extension, and the requirement for anomalous melt generation beneath the EARS is inescapable.

It has been argued that melt anomalies in the upper mantle might be not due to plumes but due to anomalous water content. If this were the reason for the high melt amounts in the EARS, only at small extension widths anomalously high melt amounts would be expected. The above comparison, however, shows that also at larger extension width the melt production is anomalously high. This cannot be explained if during early stages melting would dehydrate the mantle, producing an essentially dry asthenosphere at later rift stages.

\subsection{Model restrictions}

As mentioned above the models are purely viscous, and elasticity has been neglected. As shown by Schmeling et al. (2008) this assumption is valid for plate tectonic lithospheric deformations such as subduction as long as lithospheric viscosities do not exceed values of $10^{23} \mathrm{~Pa}$ s. A useful measure of the potential importance of elasticity is the Maxwell-time $t_{\mathrm{M}}=$ $\eta_{\mathrm{s}} / \mu$, where $\mu$ is the shear modulus. Inspecting the viscosity distributions of the models shows that during the first 2 Myr of rifting (of model 1 or 2) the expected Maxwell-time within the lithosphere would be well below 0.1 Myr within most parts of the lithosphere and asthenosphere. This indicates that even if visco-elasticity would have been used, elastic stresses would have been mostly relaxed. Only during the late rifting stage (during and after break up) the estimated Maxwell-time within the lithosphere increases to above 1 Myr, i.e. 
reaches and exceeds the model time. During theses late stages some elastic straining might accompany the otherwise small lithospheric deformation. The models with smaller rift velocities have effective viscosities somewhat higher than in model 2. However, the associated Maxwell-times still remain well below the longer model times..

Although plastic rheology has been used in the lithosphere, no strain localization along faults has been observed in these models. While it cannot be excluded that the numerical resolution within the plastic zones is too coarse to resolve strain localization, three layers of ductile (power law) rheology within the upper, crust, lower crust and the upper mantle may moderate the straining and work against strain localization in the thin plastic layers between. Furthermore, as in the present model a non-flexible top boundary has been assumed (topography is calculated a posteriori), faulting with fault scarps at the surface is prohibited.

As model 4 did not assume a localized thermal anomaly as initial condition (c.f. Fig. 1), lithospheric necking at $\mathrm{x}=0$ did not occur within 3 Myr as it was observed for models $1-3$ but was delayed by about $2-3$ Myrs. Thus, the total extension leading to rifting might vary by a factor of approximately 2 depending on the magnitude of localized lithospheric weakening.

\subsection{Lithospheric weakening due to melt infiltration}

The acceleration of rifting due to the occurrence of melting has been discussed in section 3.3 and turned out to be only moderate. Melt weakening only occurred in the partially molten asthenosphere, while within the overlying unmolten lithosphere the effect of melt is only indirectly by slightly enhanced buoyancy forces. However, it might be possible that the initially strong, unmolten lithosphere might be weakened by penetration magma via dykes (Buck, 2004; 2006). Thus the present model with melting represents a strong end member model. In an extreme magmatic weakening model the long term presences of a melt filled dyke cutting through the whole lithosphere is required to reduce the lithospheric strength and can be regarded as a weak end member model (Buck, 2004). An intermediate weakening model has been proposed in the ridge jump model by Mittelstaedt et al. (2008), where within the magma ascent zone within the lithosphere a heat source term with Gaussian distribution has been assumed (neglecting latent heat and melt buoyancy).

\section{Conclusions}

The numerical models allow to draw a number of interesting conclusions. As for the dynamics of rifting, they may be summarized as: 
- Rifting occurs in three stages: 1) distributed extension, with superimposed pinch and swell instability, 2) lithospheric necking, 3) continental break up, oceanization. The timing of the transition from stage 1) to 2) depends on the presence and magnitude of a localized perturbation, and occurs typically after 100 - $150 \mathrm{~km}$ of total extension for the lithospheric system studied here.

- The dynamic contribution to topography during rifting is rather high and amounts to 1 $-2 \mathrm{~km}$ positive topography. If rifting stops, immediate subsidence by this amount is predicted.

The effect of melting on rifting may be summarized as follows:

- Solidification of ascended melt beneath rift flanks leads to basaltic enrichment and underplating beneath the flanks, often observed at volcanic margins

- After continental break up a second time-dependent upwelling event off the rift axis beneath the continental margin is found, producing further volcanics

- Melting has almost no or only a small accelerating effect on the local extension value ( $\beta$-value) for a constant external extension rate.

- Melting has an extremely strong effect on the upwelling velocity within asthenospheric wedge beneath the new rift. High upwelling velocities are found even for very small rifting velocities.

- Variations of full rift velocities between 10 and $40 \mathrm{~mm} / \mathrm{yr}$ do not affect the total amount of generated melt very much, sometimes even the slower model produces more melt for a given total extension. Only a decrease to $2.5 \mathrm{~mm} / \mathrm{yr}$ shows a clear reduction in melt generation rates.

- The melt induced sublithospheric convection cell is characterized by downwelling flow beneath rift flanks.

- The melt effect on topography is twofold:

- The flanks become somewhat higher (by 100 - 200m) due to depletion buoyancy

- Central subsidence is significantly amplified due to an increase in localized extension/subsidence

- Modelled magma amounts are smaller than observed for EARS. A possible explanation is a hotter mantle beneath all three rift branches of the EARS as a result of a large scale plume head 
- After extension stops, melting and convection remains active for 50 - $100 \mathrm{Myr}$, further subsidence is significant

\section{Acknowledgements}

I am grateful to Herbert Wallner and members of the RiftLink-team for inspiring discussions.

Comments by Roger Buck and an anonymous reviewer greatly improved the paper. This study was partly supported by the RiftLink research grant Schm 872/18-1 of the Deutsche Forschungsgemeinschaft, which is gratefully acknowledged..

\section{References}

Bonini, M., D. Sokoutis, G. Mulugeta, M. Boccaletti, G. Corti, F. Innocenti, P. Manetti, and F. Mazzarini, 2001: Dynamics of magma emplacement in centrifuge models of continental extension with implications for flank volcanism, Tectonics, 20(6), 10531065.

Boutilier, R. R., and C. E. Keen, 1999: Small-scale convection and divergent plate boundaries, J. Geophys. Res., 104, 7389- 7403.

Bowling, J. C. and D. L. Harry, 2001. Geodynamic models of continental extension and the formation of non-volcanic rifted continental margins. Geological Society, London, Special Publications; 2001; $\quad$ v. $187 ; \quad$ p. $511-536$; DOI: 10.1144/GSL.SP.2001.187.01.25.

Bown, J. W., and R. S. White (1995), Effect of finite extension rate on melt generation at rifted continental margins, J. Geophys. Res., 100(B9), 18,011-18,029.

Buck, W. R., 1986: Small-scale convection induced by passive rifting: The cause of uplift of rift shoulders. Earth Planet. Sci. Lett., 77, 362 . 372.

Buck, W.R. 2004. Consequences of asthenospheric variability on continental rifting. In: Karner, G.D., Taylor, B., Driscoll, N.W. \& Kohlstedy, D.L. (eds) Rheology and Deformation of the Lithosphere at Continental Margins, Columbia University Press, New York, 1-30.

Buck, W. R. (2006) The role of magma in the development of the Afro-Arabian rift system, Yirgu, G., Ebinger, C.J. \& Maguire, P.K.H. (eds) The Afar Volcanic Province within the East African Rift System. Geological Society, London, Special Publications, 259, 43-54

Chorowicz, Jean , 2005: The East African rift system. J. African Earth Sciences, 43, 379 410

Cloos, H., 1939: Hebung, Spaltung, Vulkanismus. Geol. Rundschau, 30, p. 401

Corti, G., M. Bonini, D. Sokoutis, F. Innocenti, P. Manetti, S. Cloetingh, and G. Mulugeta, 2004: Continental rift architecture and patterns of magma migration: A dynamic analysis based on centrifuge models. Tectonics, 23, TC2012, doi:10.1029/2003TC001561.

Foucher, J.-P., X. Le Pichon, J.-C. Sibuet, 1982: The ocean-continent transition in the uniform stretching model: role of partial melting in the mantle. Phil. Trans. R. Soc. Lond. A 305, $27-43$.

Ghods A., 2002: Is small scale convection responsible for the formation of thick igneous crust along volcanic passive margins? Geophys. Res. Lett., 29, No. 10, 10.1029/2001GL014408. 
Hirth, G. and D. L. Kohlstedt, 1996: Water in the oceanic upper mantle: implications for rheology, melt extraction and the evolution of the lithosphere. Earth Planet. Sci. Lett., 144, 93 - 108.

Huismans, R. S., S. J. H. Buiter, and C. Beaumont, 2005: Effect of plastic-viscous layering and strain softening on mode selection during lithospheric extension, J. Geophys. Res., 110, B02406, doi:10.1029/2004JB003114.

Kazmin, V., 1980: Geodynamic control of rift volcanism. Geol. Rundschau, Band 69, Heft 3, $757-769$.

Kendall, J.M., G. W. Stuart, C. J. Ebinger, I. D. Bastow, D. Keir, 2005: Magma-assisted rifting in Ethiopia. Nature 3161, doi:10.1038/nature03161

King, S.D., D.L. Anderson, An alternative mechanism of flood basalt formation, Earth Planet. Sci. Lett. 136 (1995)

Kirby, S. H. and A. K. Kronenberg, 1987: Rheology of the lithosphere: Selected topics. Rev. Geophys., 25, 1219 - 1244.

Kohlstedt, D., Bai, Q., Wan, Z., and Mei, S. 2000. Rheology of partially molten rocks. In N. Bagdassarov, D. Laporte, and A. B. Thompson, Hrsg., Physics and chemistry of partially molten rocks, p. 1 - 28. Kluwer Academic Publichers, Dordrecht.

Lavier, L. L. and G. Manatschal, 2006: A mechanism to thin the continental lithosphere at magma-poor margins. Nature 440, 324-328 (16 March 2006)| doi:10.1038/nature04608;

McKenzie, D. und M. J. Bickle, 1988: The volume and composition of melt generated by extension of the lithosphere. J. Petr., 29, 625-679.

NYBLADE Andrew A., 2002: Crust and upper mantle structure in East Africa : Implications for the origin of Cenozoic rifting and volcanism and the formation of magmatic rifted margins. In: Menzies, M. A., Klemperer, S. L., Ebinger, C. J., and Baker, J., eds., Volcanic Rifted Margins: Boulder, Colorado, Geological Society of America Special Paper 362, p. 15 - 26.

Mittelstaedt, E., G. Ito, and M. D. Behn, 2008: Mid-ocean ridge jumps associated with hotspot magmatism, Earth and Planetary Science Letters 266 (2008) 256-270

McKenzie, D., 1984: The generation and compaction of partially molten rock. J. Petr., 25, 713-765.

Mutter, J., W. Buck, and C. Zehnder, 1988: Convective Partial Melting 1. A Model for the Formation of Thick Basaltic Sequences During the Initiation of Spreading, J. Geophys. Res., 93(B2), 1031-1048

Nielsen, T.K. and Hopper, J.R., 2002. Formation of volcanic rifted margins: Are temperature anomalies required? Geophysical Research Letters, 29(21).

Phipps Morgan, J., 1987: Melt migration beneath mid-ocean spreading centers. Geophys. Res. Lett., 14, 1238-1241.

Ramberg, H., 1967: Gravity, Deformation, and the Earth's Crust: In Theory, Experiments and Geological Application, Acad. Press, London and New York N.Y., 214 pp.

Ramberg, H. (1971), Dynamic models simulating rift valleys and continental drift, Lithos, 4, $259-276$.

Ricard, Y. and C. Froidevaux, 1986: Stretching instabilities and lithospheric boudinage. J. Geophys. Res., 91, B8, 8314-8324

Rosendahl B R , 1987: Architecture of Continental Rifts with Special Reference to East Africa Annual Review of Earth and Planetary Sciences, Vol. 15, Pages 445-503 (doi: 10.1146/annurev.ea.15.050187.002305.

Ruedas, T., H. Schmeling, G. Marquart, A. Kreutzmann, A. Junge, 2003: Dynamics and melting of a ridge-centered plume with application to Iceland, part I: Evolution and crust production. Geophys. J. Int., 158(2), 729-743.743. 
Ruedas, T. and H. Schmeling, 2008: Kinematic models for the thickness of oceanic crust at and near mid-oceanic spreading centers. J. Geophys. Res., 113, B01402, doi:10.1029/2006JB004746.

Ruppel, C., 1995: Extensional processes in continental lithosphère, J. Geophys. Res., 100 (B12), 24,187-24,215.

Sandrin, A. and Thybo, H., 2008, Seismic constraints on a large mafic intrusion with implications for the subsidence mechanism of the Danish Basin. J. Geophys. Res, 113, B09402, doi:10.1029/2007JB005067,

Schmeling, H., 2000: Partial melting and melt segregation in a convecting mantle. In: Physics and Chemistry of Partially Molten Rocks, eds. N. Bagdassarov, D. Laporte, and A.B. Thompson, Kluwer Academic Publ., Dordrecht, pp. 141 - 178.

Schmeling, H. (2006), A model of episodic melt extraction for plumes, J. Geophys. Res., 111, 03202, doi:10.1029/2004JB003423

Schmeling H., A. Babeyko, A. Enns, C. Faccenna, F. Funiciello, T. Gerya, G. Golabek, S. Grigull , B. Kaus, G. Morra, J. van Hunen, 2007: A benchmark comparison of spontaneous subduction models - towards a free surface . Phys. Earth. Planet. Int., $171,198-223$.

Sengör, A. M. C. and K. Burke, 1978: Relative timing of rifting and volcanism on earth and its tectonic implications. Geophys. Res. Lett., 5, 419 - 421.

Sparks, D. W and E. M. Parmentier, 1991: Melt extraction from the mantle beneath spreading centers. Earth Planet. Sci. Lett., 105, 368 - 377.

Šrámek, O., Y. Ricard and D. Bercovici, 2007. Simultaneous melting and compaction in deformable two-phase media, Geophys. J. Int., 168 (3), 964-982, doi:10.1111/j.1365246X.2006.03269.x

Stamps, D. S., E. Calais, E. Saria, C. Hartnady, J.-M. Nocquet, C. J. Ebinger, and R. M. Fernandes (2008), A kinematic model for the East African Rift, Geophys. Res. Lett., 35, L05304, doi:10.1029/2007GL032781.

Su, W. and W. R. Buck, 1993: Buoyancy effects on mantle flow under mid-ocean ridges. J. Geophys.Res., 98, 12,191-12,205

Thybo, H., and C.A. Nielsen, 2009, Magma-compensated crustal thinning in continental rift zones. Nature, 457, 853-856. doi:10.1038/nature07688.

van Wijk, J.W., Huismans, R.S., ter Voorde, M. and Cloetingh, S., 2001. Melt generation at volcanic continental margins: no need for a mantle plume? Geophysical Research Letters, 28(20): 3995-3998.

Weinberg, R. F., and H. Schmeling, 1992: Polydiapirs: Multiwave length gravity structures. J. Struct. Geol., 14, 425-436.

Weissel, J. K., and G. D. Karner, 1989: Flexural uplift of rift flanks due to mechanical unloading of the lithosphere during extension, J. Geophys. Res., 94(B10), 13,919-13,95

Wernicke, B., 1985: Uniform-sense normal simple shear of the continental lithosphere, Can. J. Earth Sci., 22, 108-125.

White, R. S., G. D. Spence, S. R. Fowler, D. P. McKenzie, G. K. Westbrook, A. N. Bowne, 1987: Magmatism at rifted continental margins. Nature, 330, 3 Dec, 439 - 444

White, R. S., and D. P. McKenzie, Magmatism at rift zones: The generation of volcanic continental margins and flood basalts, J. Geophys. Res., 94, 7685- 7729, 1989 


\section{Tables}

Table 1. Properties of the contintental crust and mantle used in the modelling

\begin{tabular}{|l|l|l|l|}
\hline Variable, meaning & $\begin{array}{l}\text { Upper crust, } k=1 \\
\text { Westerly granite, }\end{array}$ & $\begin{array}{l}\text { Lower crust, } k=2 \\
\text { Clinopyroxenite }\end{array}$ & $\begin{array}{l}\text { Mantle }, k=3 \\
\text { Aheim dunite }\end{array}$ \\
\hline$\rho_{0 k}$ reference density $\left(\mathrm{kg} / \mathrm{m}^{3}\right)$ & 2630 & 3100 & 3400 \\
\hline$A_{k}\left(\mathrm{~Pa}^{\mathrm{n}} \mathrm{s}\right)$ pre-exponential factor & $8.92 \mathrm{e} 27$ & $3.48 \mathrm{e} 13$ & $1.1 \mathrm{e} 16$ \\
\hline$E_{k}(\mathrm{~J} /$ Mole $)$ activation energy & $1.39 \mathrm{e} 5$ & $3.35 \mathrm{e} 5$ & $5.35 \mathrm{e} 5$ \\
\hline$V_{k}$ activation volume $\left(\mathrm{m}^{3}\right)$ & $1 \mathrm{e}-5$ & $1 \mathrm{e}-5$ & $1 \mathrm{e}-5$ \\
\hline$n_{k}$ power law exponent & 3.4 & 2.6 & 3.6 \\
\hline$\kappa$ thermal diffusivity $\left(\mathrm{m}^{2} / \mathrm{s}\right)$ & $1-0.7 \mathrm{e}-6$ & $0.7 \mathrm{e}-6$ & $0.7-1.2 \mathrm{e}-6$ \\
\hline $\mathrm{C}_{\mathrm{k}}$ compositional field, variable & 1 for $\mathrm{k}=1$, else 0 & 1 for $\mathrm{k}=2$, else 0 & 1 for $\mathrm{k}=3$, else 0 \\
\hline Thickness $(\mathrm{km})$ & 20 & 15 & $\mathrm{n} / \mathrm{a}$ \\
\hline
\end{tabular}

Table 2. Definition of variables and values of parameters

\begin{tabular}{|c|c|}
\hline Quantity and definition & Value \\
\hline A parameter of stress delimiter & $1 \mathrm{e}-4 \mathrm{~Pa} / \mathrm{m}$ \\
\hline$a$ viscosity dependence on melt fraction & 28 \\
\hline$B$ parameter of stress delimiter & 2e7 Pa \\
\hline$c_{f}$ density factor for depletion & 0.085 \\
\hline$c_{e}$ density factor for enrichment & 0.18 \\
\hline$c_{p}$ heat capacity at constant pressure & $1300 \mathrm{~J} /(\mathrm{kg} \mathrm{K})$ \\
\hline enr basaltic enrichment due to solidification & variable \\
\hline$\dot{e}_{I I}$ second invariant of the strain rate & variable \\
\hline$f$ melting degree or depletion. & variable \\
\hline$g$ gravity acceleration & $10 \mathrm{~m} / \mathrm{s}^{2}$ \\
\hline $\begin{array}{l}H=H_{0}+H_{c} \exp \left(-\tilde{z} / d_{H}\right) \text { radiogenic heat generation with } \\
\mathrm{H}_{0} \\
\mathrm{H}_{\mathrm{c}} \\
\mathrm{d}_{\mathrm{c}}\end{array}$ & $\begin{array}{l}\text { depth-dependent } \\
5.85 \mathrm{e}-12 \mathrm{~W} / \mathrm{kg} \\
1.9 \mathrm{e}-10 \mathrm{~W} / \mathrm{kg} \\
30 \mathrm{~km}\end{array}$ \\
\hline$h_{b}$ thickness of extracted melt layer & X-dependent \\
\hline$k$ thermal conductivity $\left(=\kappa \rho c_{p}\right)$ & depth dependent \\
\hline$k_{\varphi}$ permeability & variable \\
\hline$k_{0}$ factor in permeability - porosity relation & $1 \mathrm{e}-9 \mathrm{~m}^{2}$ \\
\hline$L$ latent heat & $320 \mathrm{~kJ} / \mathrm{kg}$. \\
\hline$n$ power exponent of permeability - porosity relation & 3 \\
\hline$P$ (fluid) pressure & variable \\
\hline$t$ time & variable \\
\hline$T$ the temperature, $T_{a b s}$ absolute temperature & variable \\
\hline$\vec{v}$ velocity & variable \\
\hline$x_{i}$ or $x, y, z$ coordinates in i-direction, $\mathrm{z}$ positive upward & variable \\
\hline$\tilde{Z}$ depth, positive downward & variabel \\
\hline$\alpha$ volumetric thermal expansivity & $3.7 \mathrm{e}-5 \mathrm{~K}^{-1}$ \\
\hline$\delta_{i j}$ unit matrix (Kronecker symbol) & 1 or 0 \\
\hline$\varepsilon$ emplacement rate of basaltic layer in thickness per time & X-dependent \\
\hline$\Gamma$ rate of melt generation (melt mass per volume and time) & variable \\
\hline$\varphi$ melt fraction, & variable \\
\hline
\end{tabular}




\begin{tabular}{|l|l|}
\hline$\psi$ dissipation rate & variable \\
\hline$\eta_{f}$ melt viscosity & $3 \mathrm{~Pa} \mathrm{~s}$ \\
\hline$\eta_{s}$ effective shear viscosity of the (porous) matrix & \\
\hline$\eta_{b}$ effective bulk viscosity of the (porous) matrix & \\
\hline$\rho_{f}$ melt density & $3012 \mathrm{~kg} / \mathrm{m}^{3}$ \\
\hline$\tau_{i j}$ deviatoric stress tensor, $\tau_{I I}$ second invariant & variable \\
\hline & \\
\hline & \\
\hline & \\
\hline
\end{tabular}

Table 3. Summary of the models

\begin{tabular}{|c|c|c|}
\hline Model No & Parameters & Description \\
\hline 1 & $\begin{array}{l}\text { Parameters of Table } 1 \\
\text { and 2, melting } \\
\text { swithched off }\end{array}$ & $\begin{array}{l}\text { Rift model without melting, one-sided } \\
\text { rifting velocity } 2 \mathrm{~cm} / \mathrm{yr}\end{array}$ \\
\hline $1 \mathrm{a}$ & -" - & $\begin{array}{l}\text { Velocity boundary conditions }(2 \mathrm{~cm} / \mathrm{yr}) \\
\text { set to zero at } 3 \mathrm{Myr} \text {, rifting stopped }\end{array}$ \\
\hline 2 & $\begin{array}{l}\text { Parameters of Table } 1 \\
\text { and } 2\end{array}$ & $\begin{array}{l}\text { Melting, melt is extracted if } 2 \% \text { are } \\
\text { exceeded, extracted melt is introduced in } \\
\text { equ. } 11 \text { to follow the evolution of the } \\
\text { basaltic layer. One-sided rifting velocity } 2 \\
\mathrm{~cm} / \mathrm{yr}\end{array}$ \\
\hline $2 a$ & $-"$ & $\begin{array}{l}\text { Velocity boundary conditions }(2 \mathrm{~cm} / \mathrm{yr}) \\
\text { set to zero at } 3 \mathrm{Myr} \text {, rifting stopped }\end{array}$ \\
\hline 3 & -" - & $\begin{array}{l}\text { Melting included, no extraction, i.e. all } \\
\text { melt migrates by porous flow until it } \\
\text { solidifies. One-sided rifting velocity } 2 \\
\text { cm/yr }\end{array}$ \\
\hline 4 & - " - & $\begin{array}{l}\text { As model } 2 \text { but with a } 100 \mathrm{~K} \text { hotter } \\
\text { temperature anomaly at } 200 \mathrm{~km} \text { depth to } \\
\text { mimic hot plume influx. One-sided rifting } \\
\text { velocity } 2 \mathrm{~cm} / \mathrm{yr}\end{array}$ \\
\hline 5 & - - - & $\begin{array}{l}\text { As model } 2 \text { but one-sided rifting velocity } \\
5 \mathrm{~mm} / \mathrm{yr}\end{array}$ \\
\hline 6 & - “- & $\begin{array}{l}\text { As model } 2 \text { but one-sided rifting velocity } \\
1.25 \mathrm{~mm} / \mathrm{yr}\end{array}$ \\
\hline
\end{tabular}




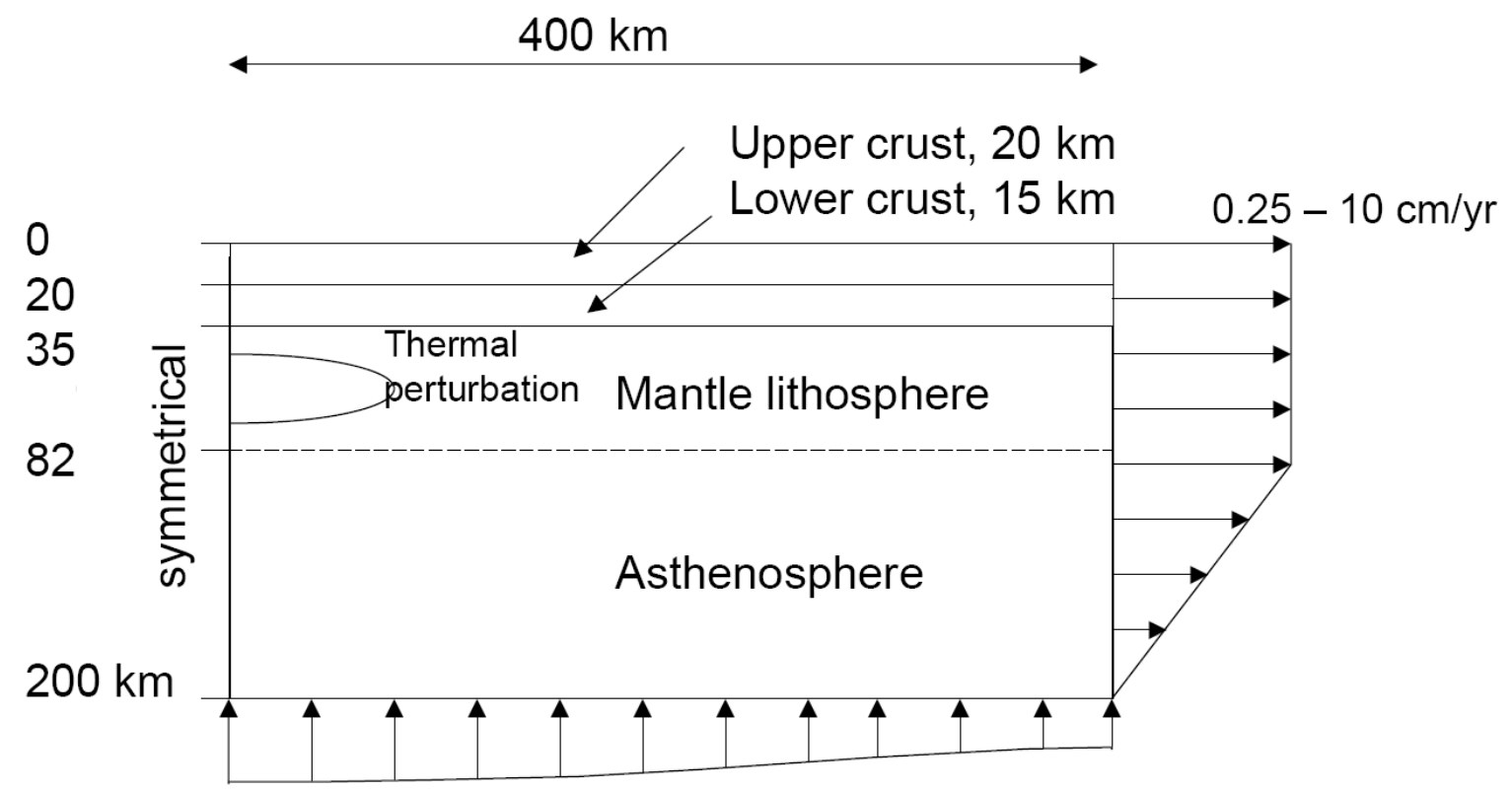

Figure 1. Model setup 

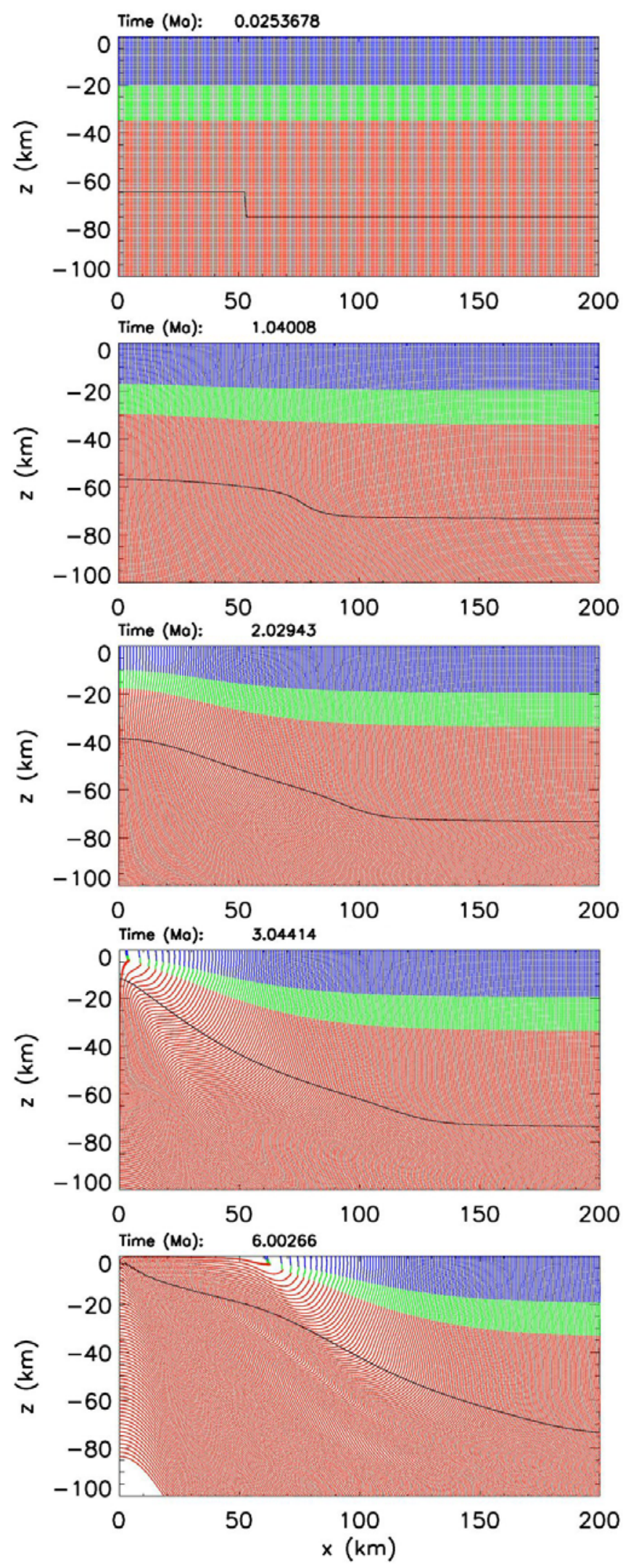

Fig. 2. Different stages of a lithospheric extension model without melting. Half-rift velocity is $2 \mathrm{~cm} / \mathrm{yr}$. Lithosphere-astrhenosphere boundary (solid curve) is defined as the $1200{ }^{\circ} \mathrm{C}$ geotherm. Only part of the full model is shown. The marker field clearly shows the finite deformation field. 

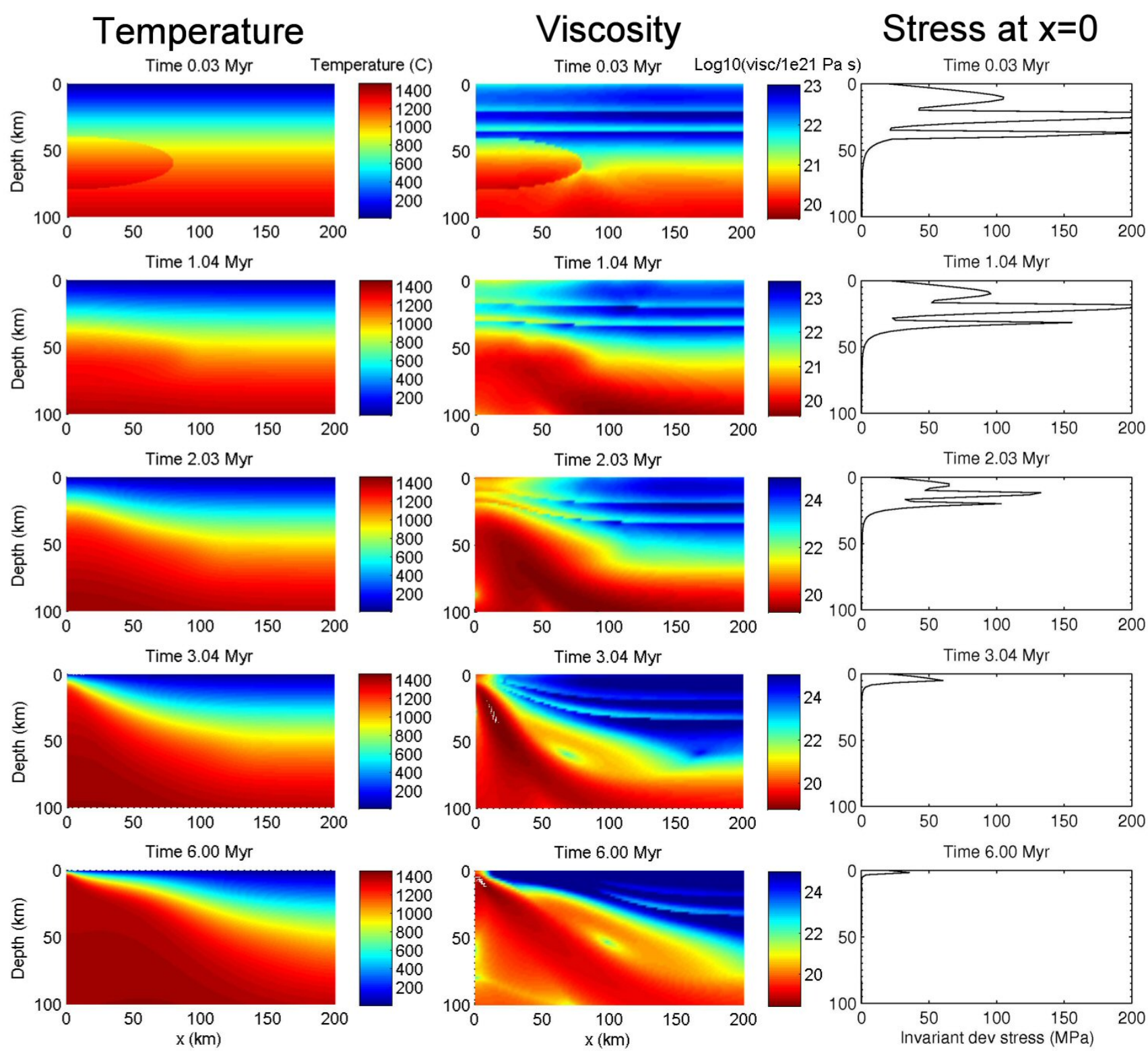

Fig. 3. Temperature, logarithm of viscosity scaled by 1 Pa s, and second invariant of the deviatoric stress tensor of the rift model (without melting) shown in Fig. 2. 

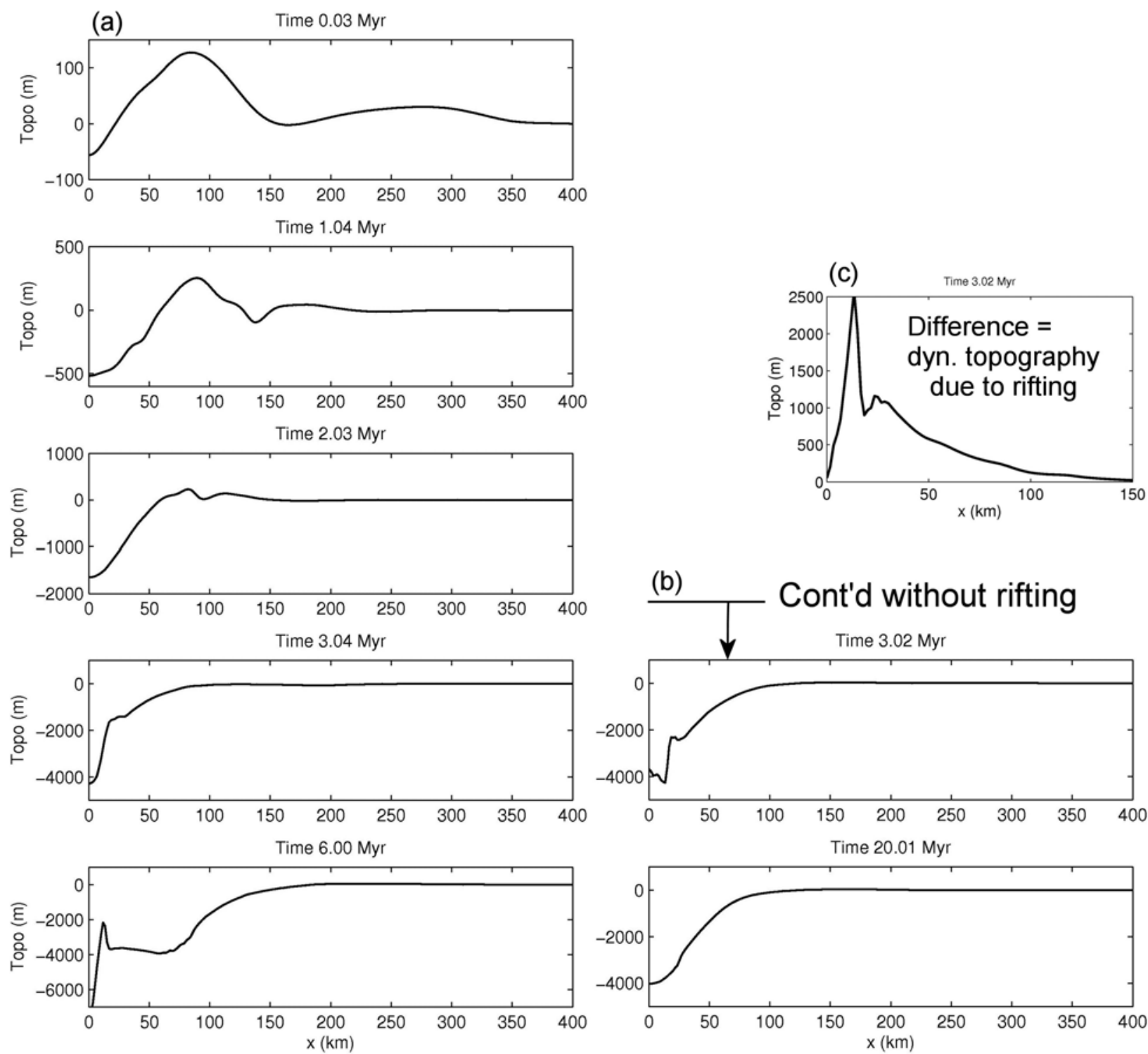

Fig. 4 (a) Evolution of dynamic topography of model 1 at some early stages until break up of continental crust (c.f. stages shown in Fig.3). Note the different scales. Elasticity, erosion and sedimentation are not accounted for. Because of the undetermined constant of integration when calculating topography, the zero-level for topography is arbitrary, it is defined as the undisturbed topography at the right hand side of the model. (b) In this model rifting is stopped at 3 Myr and the subsequent evolution of the extinct rift is shown. (c) Difference of topography immediately before and after stopping rifting. This shows the dynamic effect of rifting on topography. The exact maximum peak value may be beyond numerical resolution. 


\section{Melt generation rate}
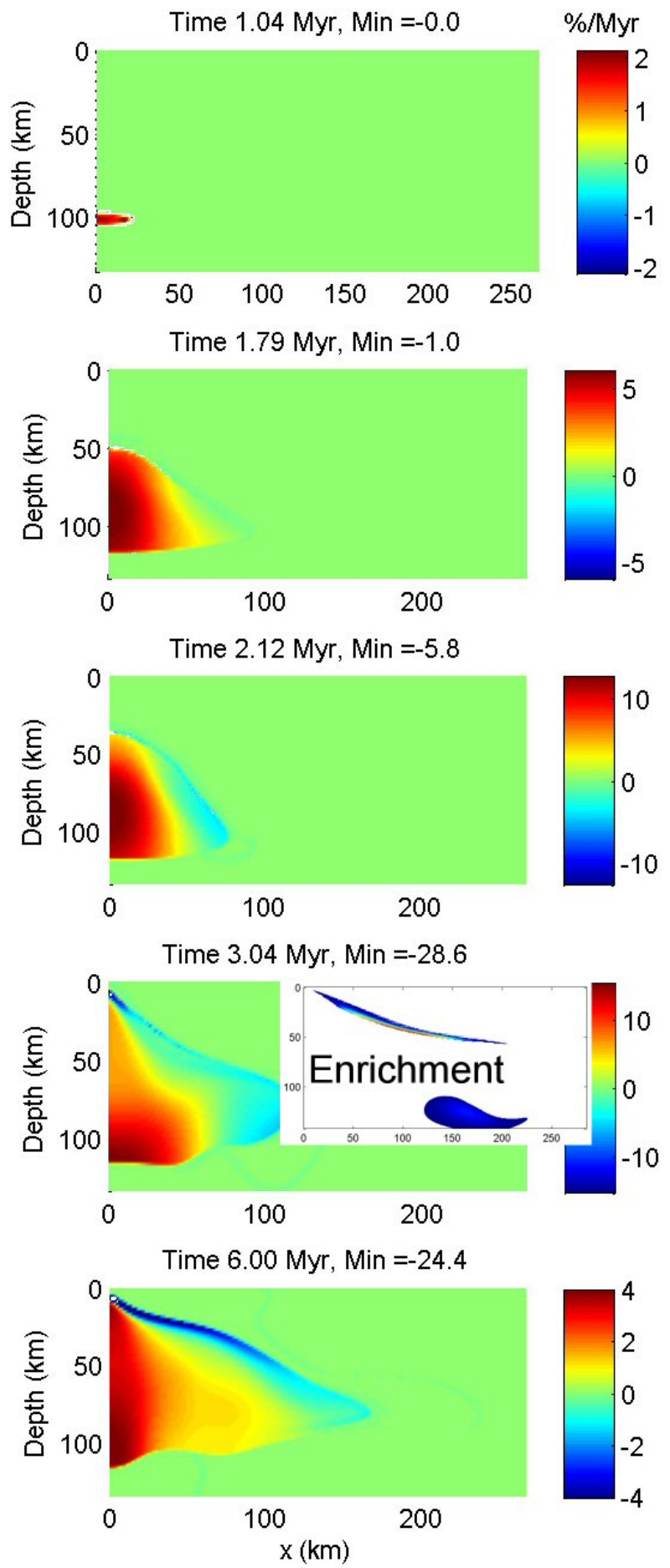

Fig. 5 Melt generation rate of model 2 at different times. Model 2 is equal to model 1, except that melting is accounted for. Negative values (blue) mean solidification. Note the different scales in the melt generation rate. The inset shows a snap shot at 3 Myr of the basaltic enrichment field, which forms as a consequence of solidification and advection. Maximum enrichment value is about $1 \%$. Note the deeply seated enrichment blob which moves towards the rift axis. 

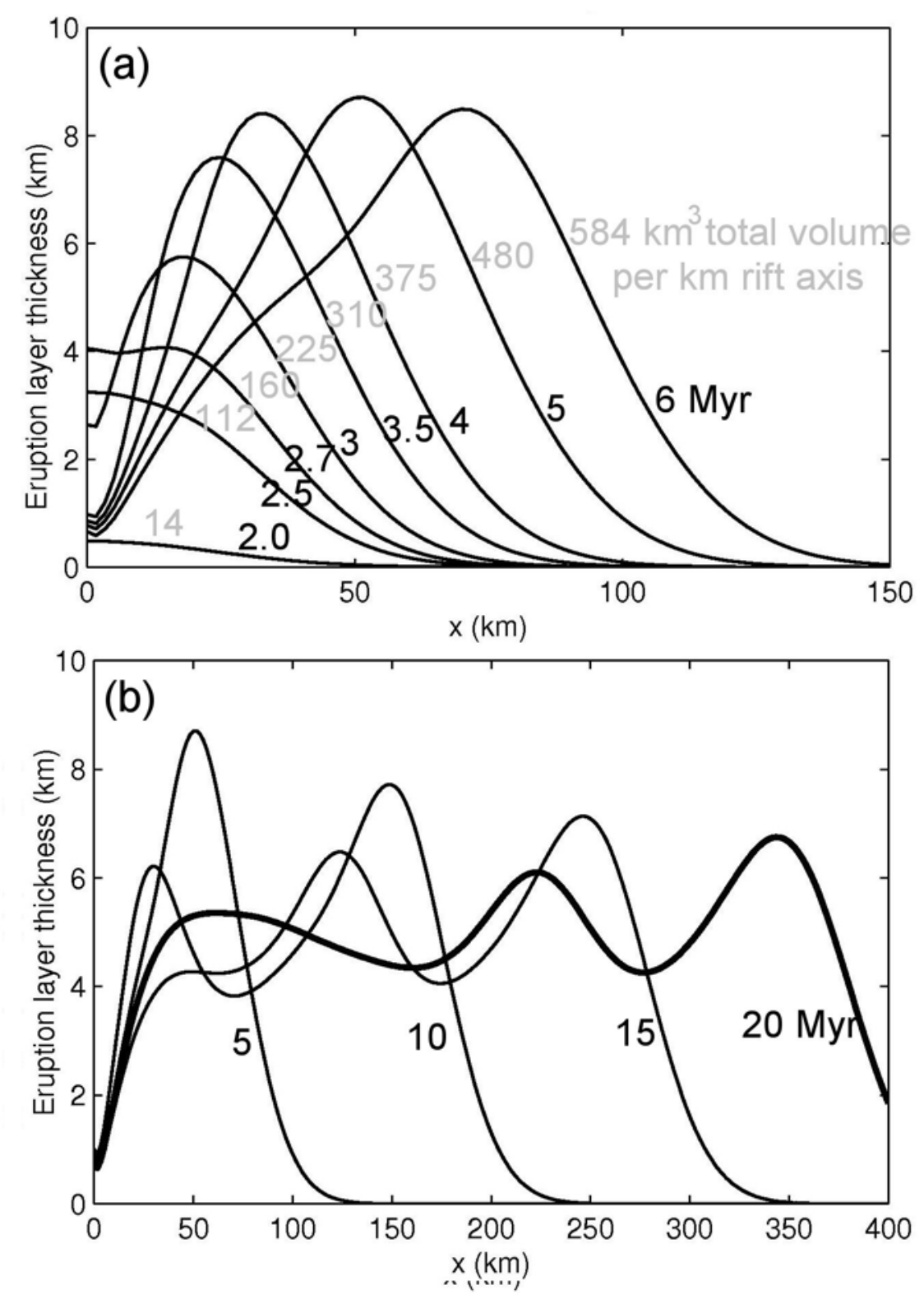

Fig. 6. Extracted basaltic material of model 2 after different times. The corresponding amounts of extension are $40 \mathrm{~km}$ after $2 \mathrm{Myr}, 100 \mathrm{~km}$ after 5 Myr etc.. (a) Rift stage, (b) Ocean formation up to $20 \mathrm{Myr}$ of continuous rifting/spreading. 

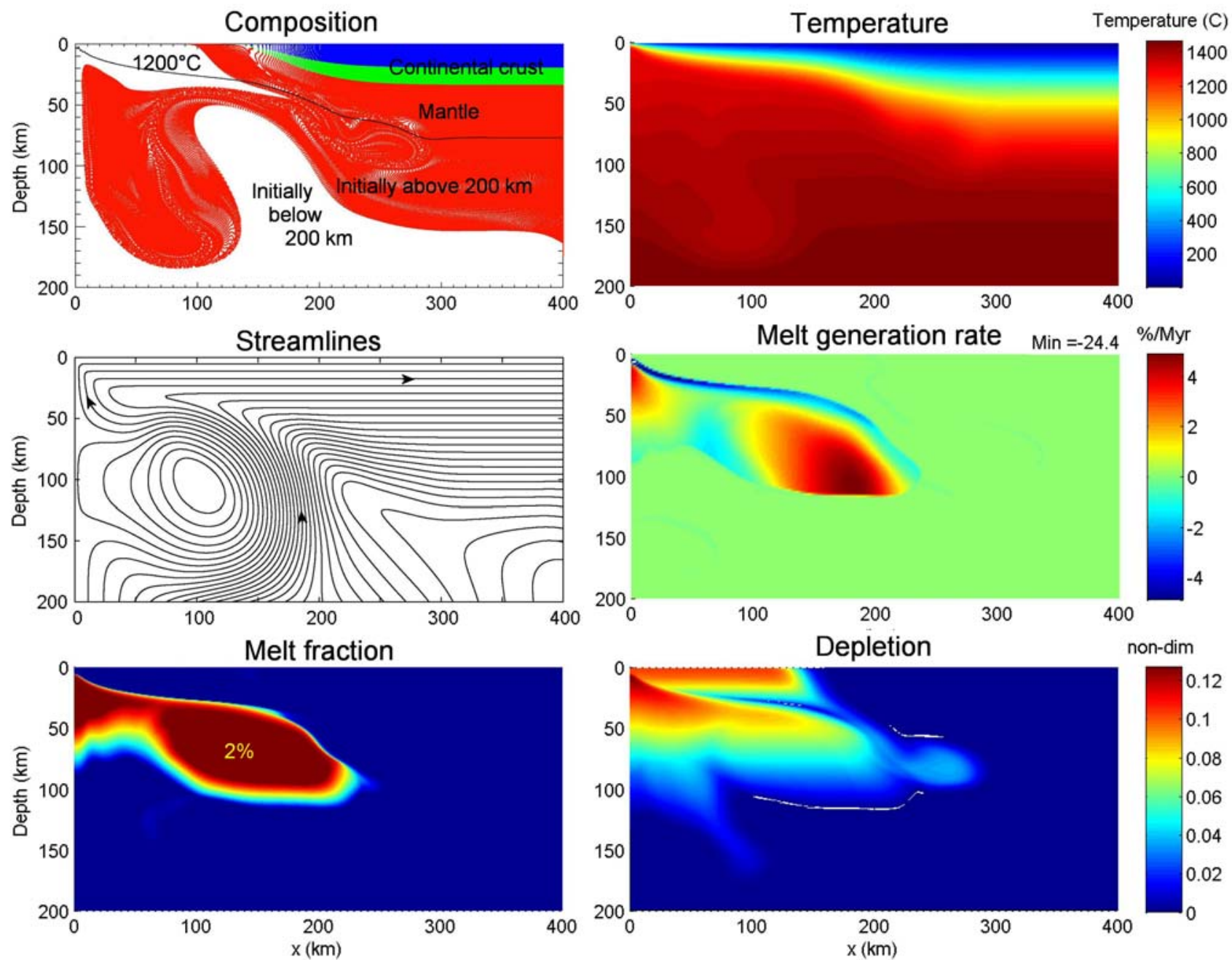

Fig. 7. Snapshot of continental break-up model (model 2) at $10 \mathrm{Myr}$ or $200 \mathrm{~km}$ (half-) opening. The composition shows, in different colours, the upper (blue) and lower (green) crust and the compositionally uniform mantle (red and white). The white mantle region was original at a depth below $200 \mathrm{~km}$. The $1200^{\circ} \mathrm{C}$ geotherm is shown as an indication of the base of the thermal lithosphere. The streamlines show that the upwelling at this time is situated beneath the continental margin, and only a weak upwelling is present beneath the spreading axis, underlain by a downwelling. This flow configuration results in two separated melt generation zones. 

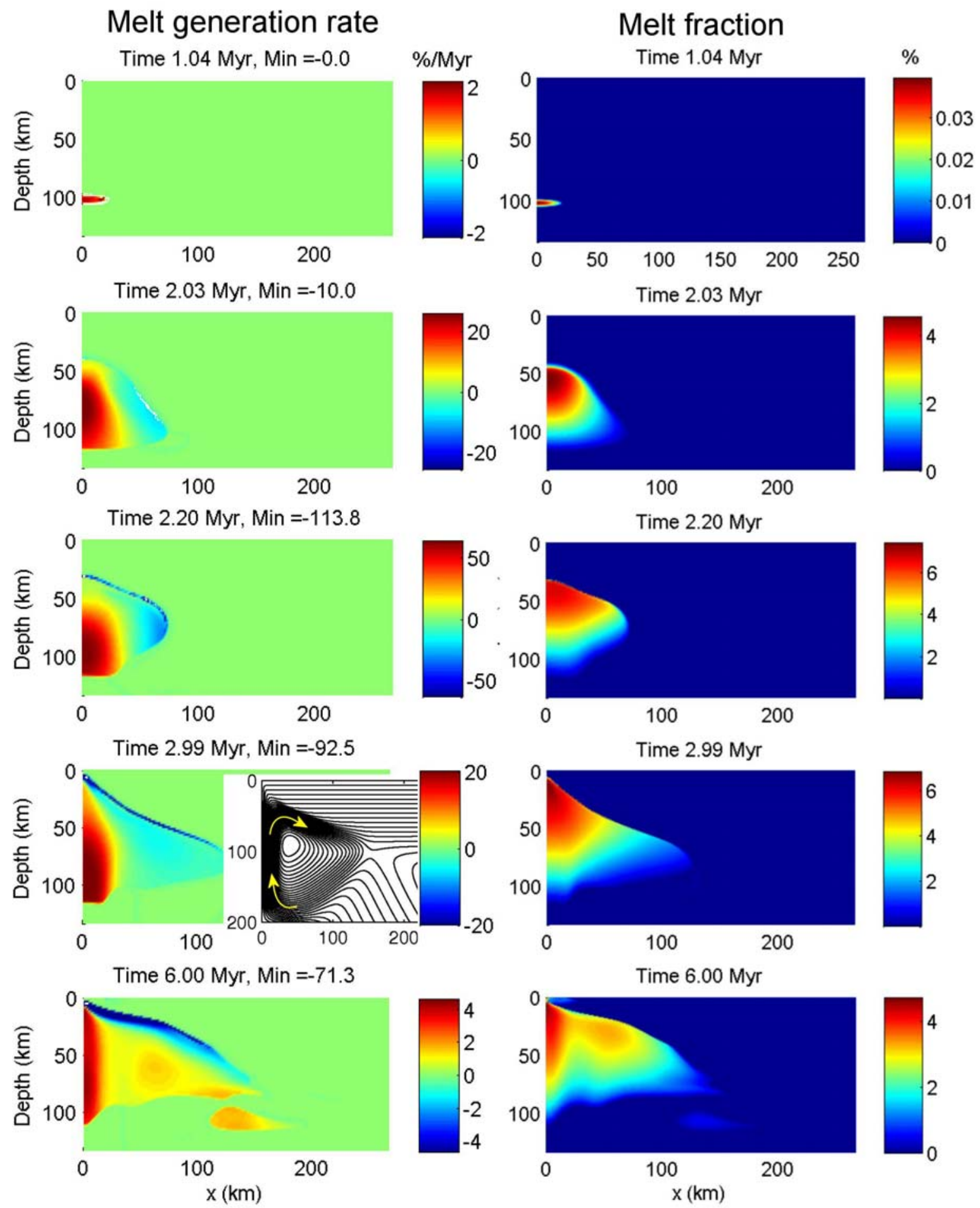

Fig. 8. Model 3: As model 2 but without melt extraction. The inset shows the flow structure at $3 \mathrm{Myr}$, indicating a narrow upwelling at the rift axis associated with an oblique downwelling beneath the rift flank. 


\section{$1.25 \mathrm{~mm} / \mathrm{yr}, 48 \mathrm{Myr}$}
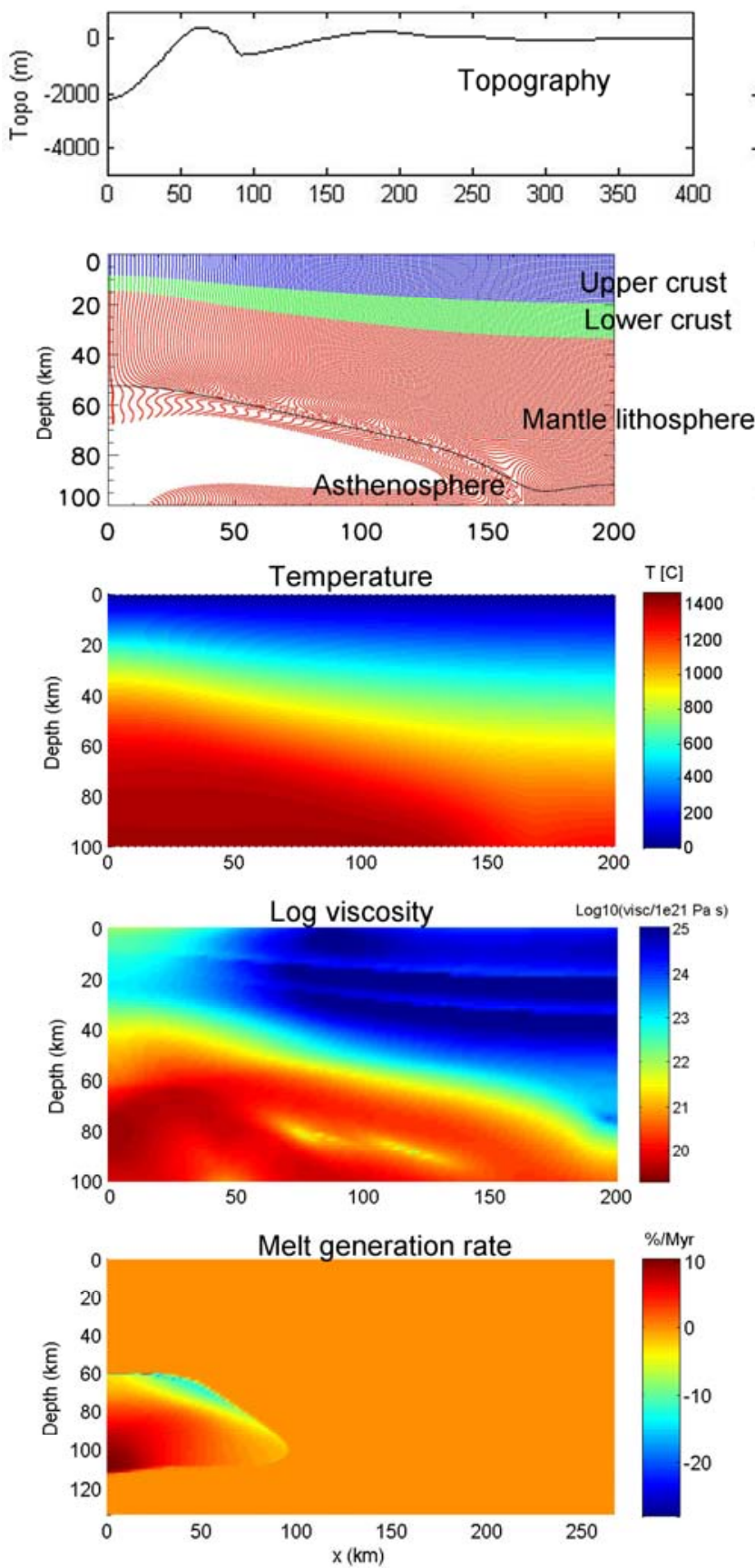

$5 \mathrm{~mm} / \mathrm{yr}, 12 \mathrm{Myr}$
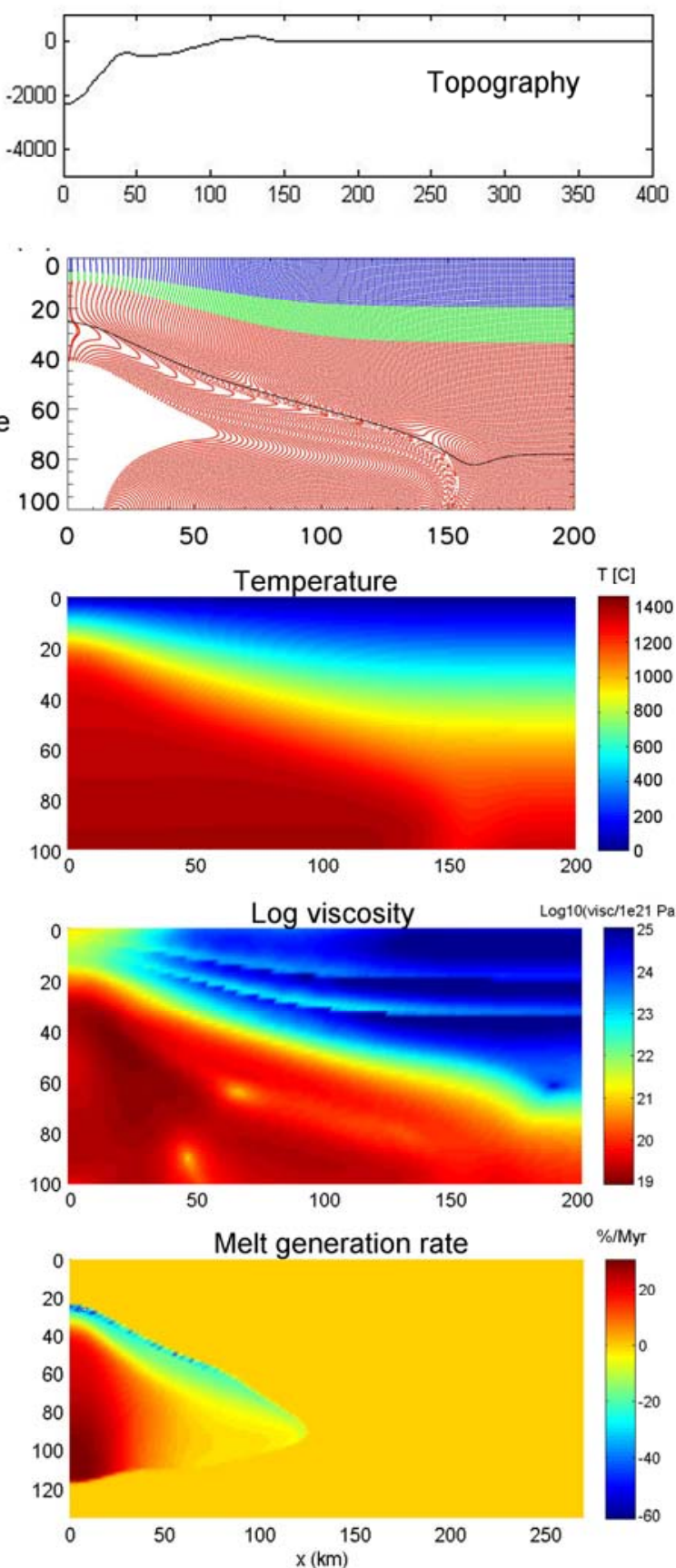

Fig. 9.Rifting models with slower rifting velocities, taken at snapshots corresponding to 3 Myr of model 2 or a total (double-sided) rift extension of $120 \mathrm{~km}$. Left column: Model 6 with $1.25 \mathrm{~mm} / \mathrm{yr}$ (one-sided) extension rate. Right column: Model 5 with $5 \mathrm{~mm} / \mathrm{yr}$ (one-sided) extension rate 
(a)

Extension factor

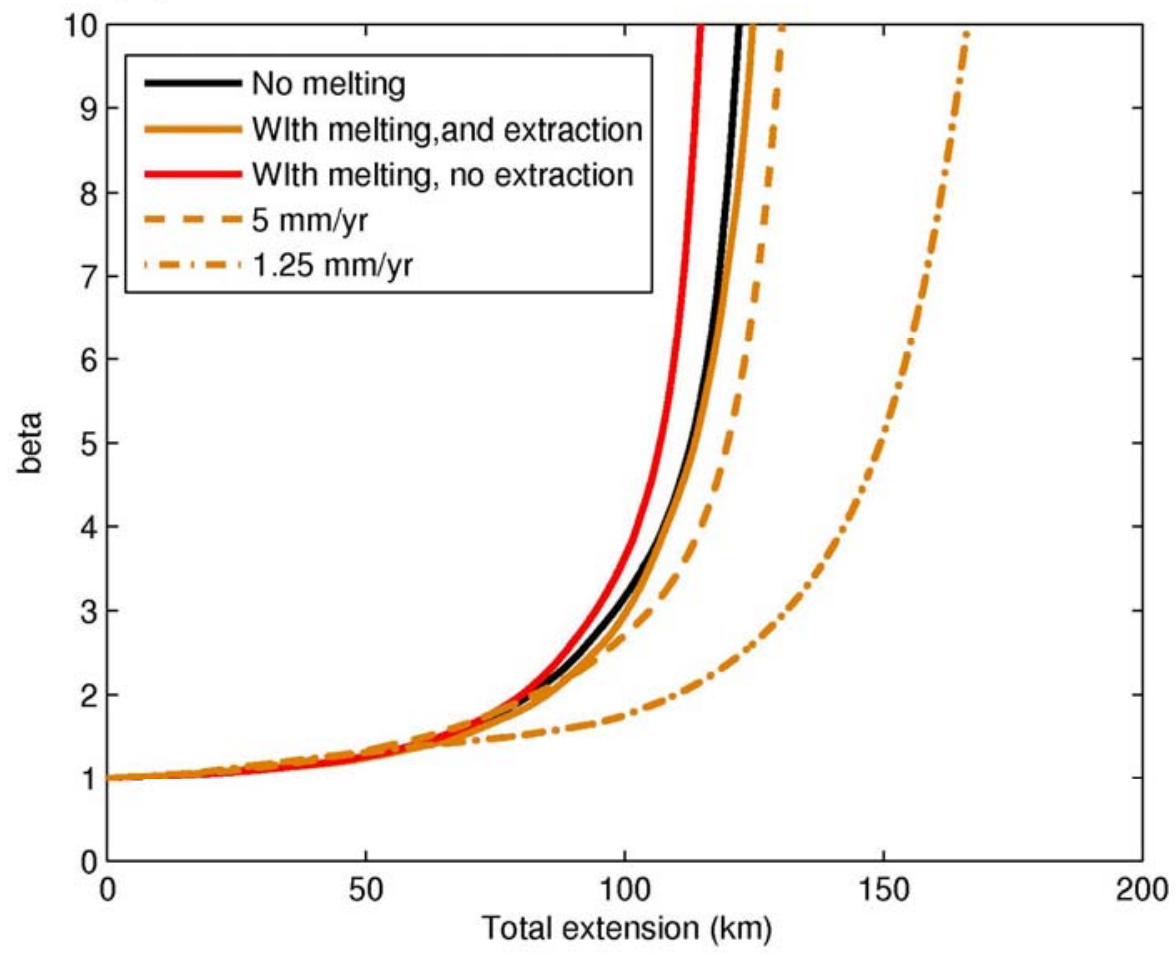

(b)

Max. vertical velocity

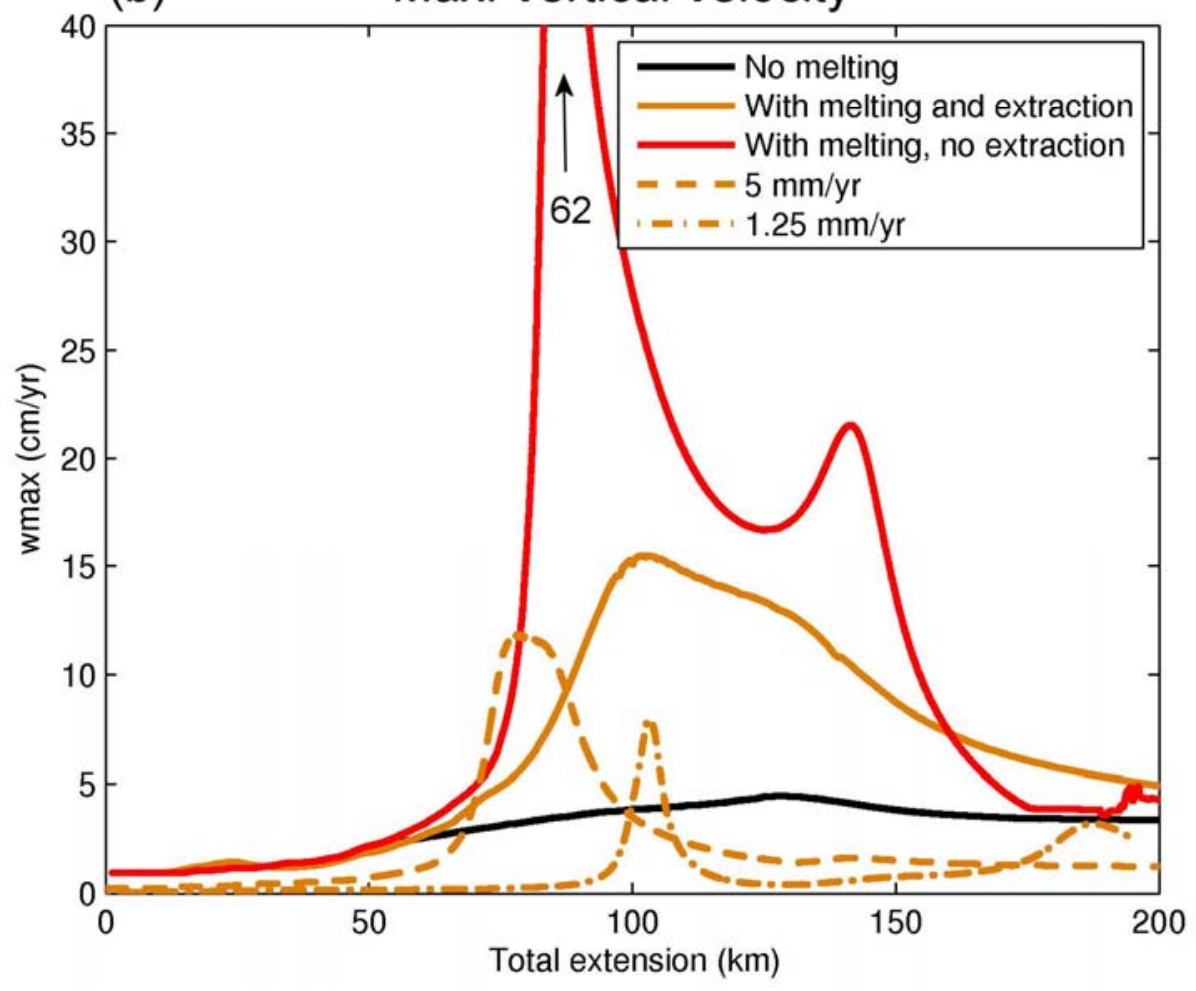

Fig. 10. Comparison of models 1 (without melting), 2 (with melting and melt extraction), 3 (with melting without extraction), 4 and 5 (as model 2, but reduced one-sided rifting velocity as indicated. (a) Extension ( $\beta$-factor) at the rift axis as a function of time. (b) Maximum vertical velocity within the asthenosphere at the rift axis as a function of time. 


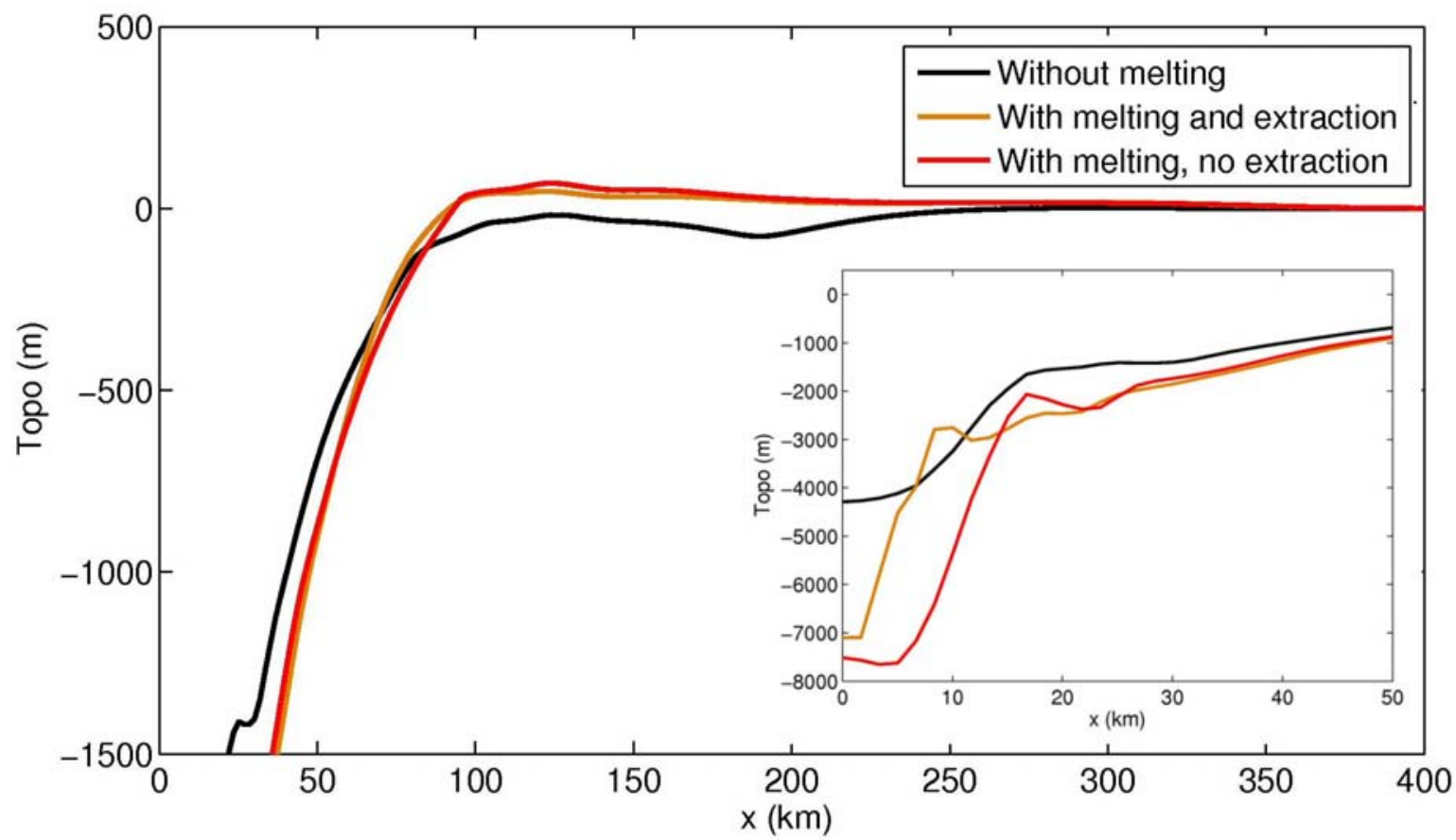

Fig. 11. Comparison of topography of the different models 1,2 and 3 at 3 Myr. The inset show a close up of the inner $50 \mathrm{~km}$ of the rift zone. 


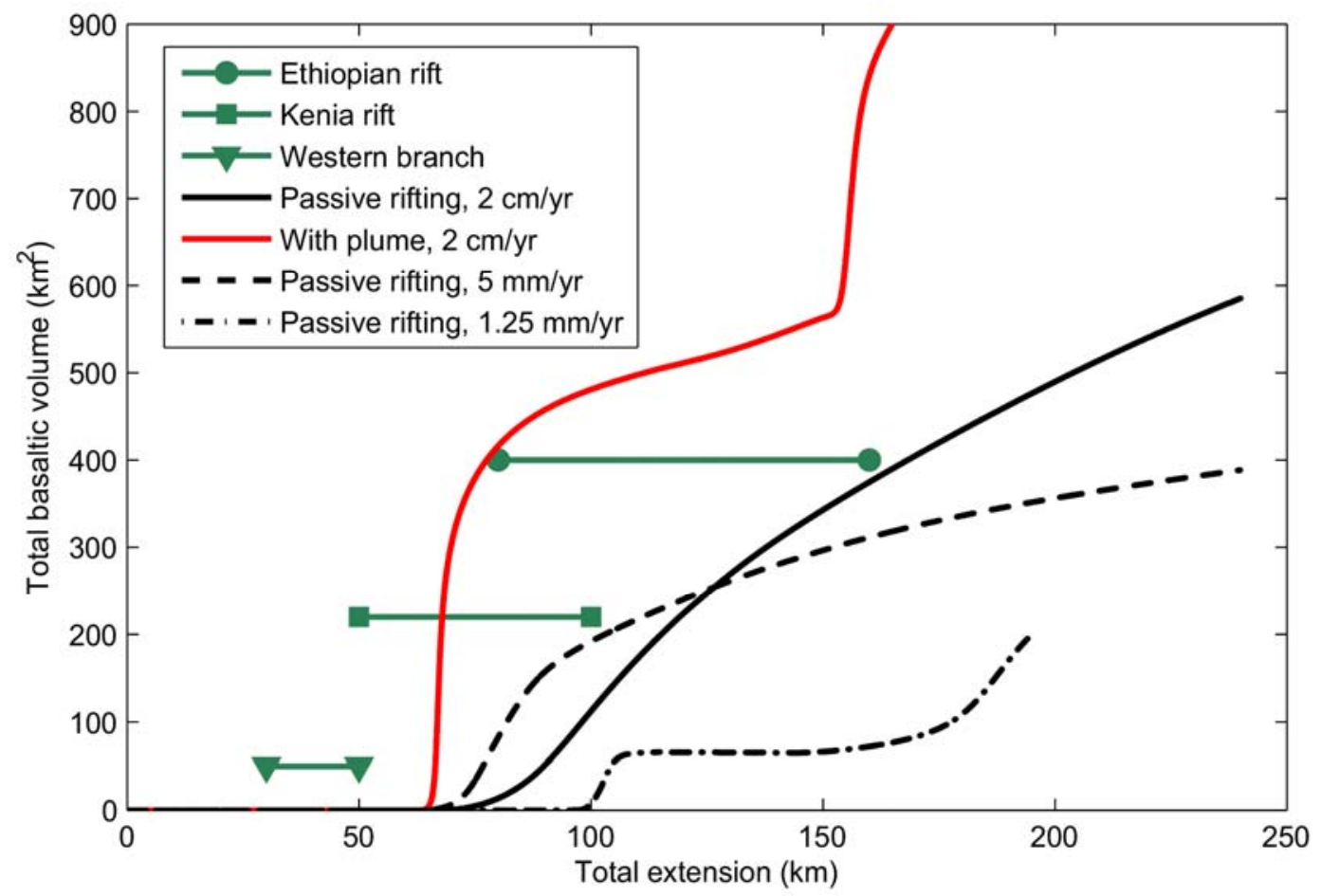

Fig. 12. Comparison of total basalt volumes extracted from model 2 (black curve), model 4 with hotter asthenospheric influx mimicking a plume (red curve), models 5 and 6 with reduced rifting rates (dashed and dash-dotted curves) and three estimates of basaltic volumes of the East Africa Rift System. For the numerical models the abszissa shows the externally prescribed total extension, for the EARS, the abszissa represents the width of the rift. 